\title{
The ECL optimization and experiment of HSPMSM with improved method
}

\author{
Xu Liu ${ }^{1,2 *}$, Member, IEEE \\ ${ }^{1}$ School of Instrumentation Science and Optoelectronics Engineering, Beijing University of Aeronautics and \\ Astronautics, Beijing 100191, China \\ ${ }^{2}$ Beijing Engineering Research Center of High-Speed Magnetically Suspended Motor Technology and \\ Application, Beijing University of Aeronautics and Astronautics, Beijing 100191, China \\ E-mail: liuxu001@buaa.edu.cn
}

\begin{abstract}
The eddy current loss should be optimized to be as less as possible for the stability of permanent magnet in high speed permanent magnet synchronous motor (HSPMSM) rotor and ensure the high efficiency and low temperature of the motor. This paper analyzes the eddy current distribution in rotor, with consideration of the conflict of the thickness of sleeve and diameter of the rotor, calculating the eddy current loss (ECL) and the thermal distribution via Separation of variables method for solving Maxwell's equations with analytical hieratical model of ECL constructed. The optimization result of ECL of the HSPMSM whose power and rated speed is $30 \mathrm{kw} 48000 \mathrm{r} / \mathrm{min}$ can be got by multi-objective optimization method, combined weighting coefficient method and traversal algorithm based on chaotic local search particle swarm optimization (CLSPSO), utilizing ECL analytical model and other analytical constraints. Related experiment and measurement has been implemented with new approach of loss separation.
\end{abstract}

Index Terms - eddy current loss, multi-objective optimization (MOO), electromagnetic analysis, equivalent hierarchical method

\section{INTRODUCTION}

As for the HSPMSM, the ECL of rotor of which has higher speed occupies higher percentage of total loss especially in similar power level [1-4]. The component of ECL consists of spatial harmonic loss and time harmonic loss which occupies the mainly part when the HSPMSM reach more fast speed[5-7]. The higher ECL causes higher temperature rise and higher thermal stress, which threatens the operating stability of HSPMSM. The ECL in the rotor is usually appears significant when the PMSM operates at a higher speed [8].the harmonics ECL caused by space harmonics and time harmonics of flux density increase the temperature of rotor. This article mainly focus on investigation of ECL mainly caused by harmonics in rotor and the reduction approach of it via optimization process.

With consideration of the PWM harmonics and the ECL caused by differential electromotive force, the main source of ECL is caused by harmonics [9-15]. Therefore, The ECL in rotor can be separated by each order harmonic ECL, which is asynchronous with the stator current, on which we based, the ECL analysis method of asynchronous motor can be used in PMSM, by which each order harmonic ECL can be calculated. During that computation process, the equivalent current sheet method can be utilized in equal to stator current density.

Since the ECL impacts the performance of the HSPMSM in every aspect, the optimization should be considered both in temperature rise and structural strength of rotor, as well as based on the ECL amount. The conventional multi-objective optimization mainly focused on weighted coefficient method [16-18], since its stable convergence, however, with the instability to arrive at the PARETO front ignored.

Besides, the GA [19] and other evolution algorithms such as
Response Surface Methodology [20].et have been utilized in MOO with practical model involved [21-22]. The traversal algorithm runs lack of stability of convergence [23-24]. Thus, the combination of those two approaches can be utilized in MOO of HSPMSM via improved algorithm and adjusted parameters. The constraints are often transformed to penalty functions added to the objective function based on particle swarm optimization (PSO) [25-26] and harmony search (HS) [27] algorithm.et [28-29].

ECL and other loss of HSPMSM are separated and measured by drag system, which approach has been implemented on varieties of motors. The computation of core loss and copper loss of coils has related mature method. The core loss [30-35] is calculated by loss coefficient method, while the copper loss [36-43] can be calculated by analysis method with AC effect considered. Besides, to measure the loss effectively and precisely, some improve modification of experiment has been proposed [44-45].

This article first establishes the mathematical model of ECL by analytical electromagnetic field method, accounting for the curvature effect of rotor and the cylindrical magnet. The calculation results including equivalent hierarchical method and other methods such as FEM, experiment approaches are compared, on which based, the analytical expression of ECL can be deduced and applied to MOO, which combine the weighting coefficient method and traversal algorithm based on penalty function, generated from geometric, strength and thermal constraints. There exists conflict among the thickness of sleeve, length of airgap and outer diameter of rotor, in virtue of the electromagnetic effect, amount of ECL and the stress existing in sleeve, with temperature rise.et, resulting in contrary correlativity together, such as increase of sleeve thickness leads to improve its strength, however, also increase ECL in it, and so on, which brings about the significance of MOO. The results of MOO, processed by chaotic local search particle swarm optimization (CLSPSO) algorithm, have been validated by finite element method (FEM) via electromagnetic analysis, thermal simulation and structural strength computation. Afterwards, the prototype is manufactured and implemented experimental test for loss separation. The performance of HSPMSM has been validated via drag system, besides, which is utilized to separate ECL. Core loss and coil loss are separated by measurement via related instrument combined with some calculations, with consideration of AC effect in copper loss of coils and proper modification of loss coefficient in core loss. More practical approach on wind frictional loss separation has been proposed and proved by experimental measurement.

\section{ANALYTICAL MODEL OF ECL}

The structure of the 30kw HMPMSM shows in Fig.1(a), 
consisting of motor, magnetic bearing, touchdown bearing, motor enclosure and other parts, in which the main loss generated in the motor part, consisting of stator, coils, sleeve wrapped outside of rotor, and permanent magnet, a cylinder embedded in the middle of it, comes down to the sketch map which is illustrated in Fig.1(b), of which the equivalent hierarchical model is left middle in Fig.1(b). The section of motor part of HSPMSM is in the right of Fig.1(b).

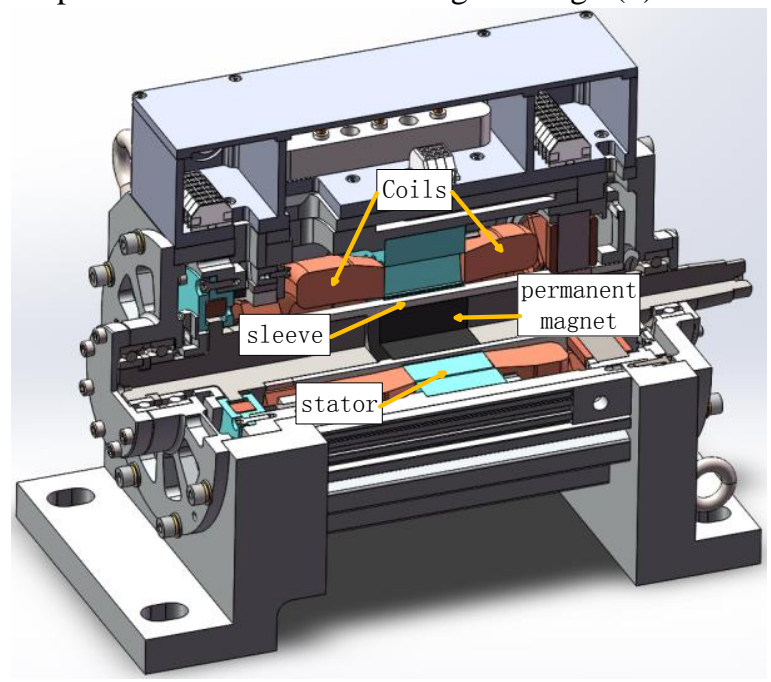

(a) the structure of the $30 \mathrm{kw}$ HMPMSM

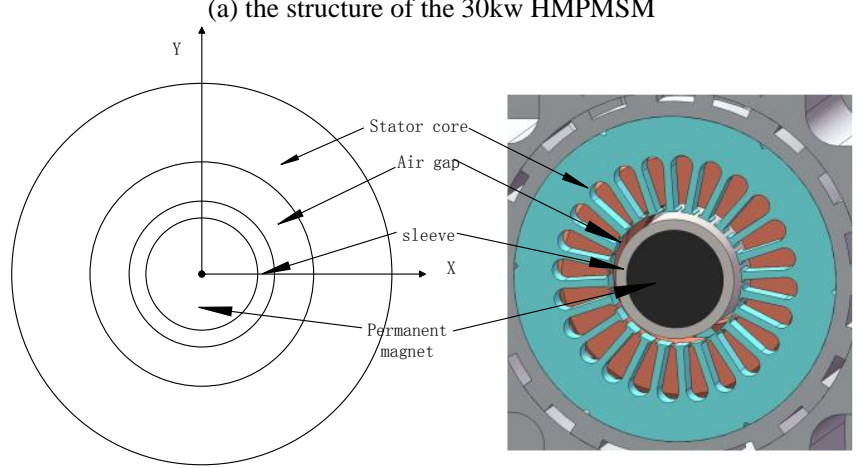

(b)the sketch map of the $30 \mathrm{kw}$ motor

Fig 1. The structure of HMPMSM and the sketch map of motor

The eddy current here we mainly consider the time harmonics which is produced by PWM modulation, ignoring the one generated by the spatial distribution of the windings and other spatial harmonics, such as tooth permeance harmonics.

The 30kw HSPMSM here, 48000r/min rated speed, mainly controlled by Three-phase six-step control strategy which permit two-phase simultaneous conduction.

With consideration of the ending effect, we compute the ECL by 3-d electromagnetic approach as the followings:

The structure of the motor, as is shown in Fig 1(b), in which the component of the rotor is stratified, including the sleeve and the permanent magnet, the magnetic field intensity and magnetic induction in every layer can be derived by Maxwell's equations, of which the component form is adopted.

First, five basic approximate assumptions are made here as the followings:

a. The current (magnetic potential) of stator three phase symmetrical windings is equaled by the line current on the stator inner surface. The effect of the stator tooth is analyzed with gap coefficient.

b. There is infinite length of the stator and the rotor, only the axial component considered.

c. Stator core unsaturated, of which permeability $\mu_{s} \rightarrow \infty$ is provided, while, the hysteresis influence of ferromagnetic material is negligible.

d. The orthogonal coordinate system is adopted, ignoring the curvature impact of the rotor, otherwise we may consume a lot of time in Bessel functions.

e. The fundamental component and those time harmonics in larger proportion would be calculated as like steady alternating field.

Based on those assumptions above, the general calculation model is illustrated as Fig. 2. In coordinate system, $\mathrm{x}$ means circumferential direction, $x_{s}$ means that is fixed to stator, $x_{r}$ is fixed to rotor, y means radial direction, and the $\mathrm{z}$ represents axial direction.

Above all. The coil current $J_{s z}$ should be alternated by equivalent line current density located at the junction between the stator and air-gap, with sinusoidal distribution, transformed into Fourier series

as: $J_{s z}=\sum_{k, v} \sum_{n} \frac{4}{\pi} J_{0, k} e^{j\left(k p \omega_{k} t-a x_{s}\right)} \frac{1}{n} \sin \left(\frac{n \pi}{L_{r}}\right) z \quad n=1,3,5, \ldots$

$$
J_{0, k}=\frac{\sqrt{2} K_{d p} K_{s l o t} N_{1} I_{k}}{\pi D_{1}}
$$

Where the $K_{d p}$ is effective coil coefficient per phase of the stator winding; $K_{\text {slot }}$ is slot coefficient; $N_{1}$ is number of turns; $D_{1}$ represents inner radius of the stator; $a=\frac{\pi}{p \tau}$, $\tau=\frac{\pi D_{a}}{2 p}$ is the polar distance, where $D_{a}$ here is armature diameter, namely the inner diameter of stator here; $\mathrm{k}$ and $v$ are time and space harmonic order respectively. The related calculation expressions are listed as the followings:

$K_{\text {slot }}=\frac{\sin \left(v \frac{b_{0}}{2 R_{s}}\right)}{v \frac{b_{0}}{2 R_{s}}}$

where $b_{0}$ is slot width; $R_{s}$ is inner diameter of stator.

$K_{d p}=k_{p v} \bullet k_{d v}$

Where the coil pitch coefficient $k_{p v}$ is:

$k_{p v}=\sin \left(v \frac{\theta_{y}}{2}\right)$

Where the $\theta_{y}$ is coil pitch angle.

The coil distribution coefficient $k_{d v}$ is:

$k_{d v}=\frac{\sin \left(\frac{q \alpha_{1}}{2}\right)}{q \sin \left(\frac{\alpha_{1}}{2}\right)}$

Where $\alpha_{1}=\frac{2 p \pi}{Q}$, the electrical pitch angle; $q=\frac{Q}{2 m p}$,

the number of slot per pole per phase. Here, the number of 
slot $Q=24$, phase number $m=3$, number of pole-pairs $p=1$.

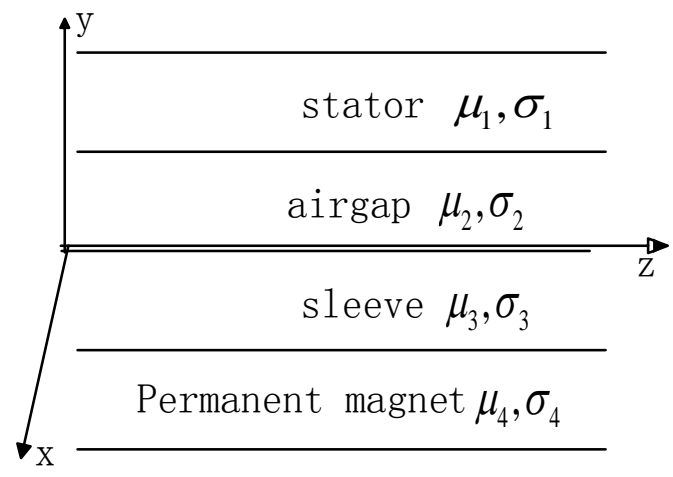

Fig.2 the 3-D equivalent hierarchical model of motor

The 3-D equivalent hierarchical model of motor and its conductivity and permeability in every layer is showing Fig.2.

The electromagnetic equations in every medium such as air-gap, sleeve and permanent magnet are listed as (7), (8), and (9) relatively:

$$
\begin{aligned}
& \frac{\partial^{2} A_{g}}{\partial x^{2}}+\frac{\partial^{2} A_{g}}{\partial y^{2}}+\frac{\partial^{2} A_{g}}{\partial z^{2}}=0 \\
& \frac{\partial^{2} A_{s}}{\partial x^{2}}+\frac{\partial^{2} A_{s}}{\partial y^{2}}+\frac{\partial^{2} A_{s}}{\partial z^{2}}=j \omega_{r} \mu_{s} \sigma_{s} A_{s} \\
& \frac{\partial^{2} A_{p}}{\partial x^{2}}+\frac{\partial^{2} A_{p}}{\partial y^{2}}+\frac{\partial^{2} A_{p}}{\partial z^{2}}=j \omega_{r} \mu_{p} \sigma_{p} A_{p}
\end{aligned}
$$

where the $A_{g}, A_{s}$, and $A_{p}$ is axial component of vector magnetic potential. As the $\left.A_{p}\right|_{y=-\infty}=C, \sigma_{s}, \sigma_{p}$ are conductivity of sleeve and permanent magnet respectively, $\mu_{s}, \mu_{p}$ are magnetic permeability respectively. Thus, the solution of (10)-(12) can be listed as:

$$
\begin{aligned}
& A_{g}=\sum_{n} C_{g n}\left(\operatorname{ch} \lambda_{n} y+D_{n} \operatorname{sh} \lambda_{n} y\right) e^{j\left(\omega_{k} t-a x_{1}\right)} \frac{1}{n} \sin \left(\frac{n \pi}{L_{e}} z\right) \\
& A_{s}=\sum_{n} C_{c n}\left(\operatorname{ch} a_{c n} y+D_{c n} s h a_{c n} y\right) e^{j\left(s \omega_{k} t-a x\right)} \frac{1}{n} \sin \left(\frac{n \pi}{L_{e}} z\right) \\
& A_{p}=\sum_{n} C_{2 n} e^{a_{n} y+j\left(s \omega_{k} t-a x\right)} \frac{1}{n} \sin \left(\frac{n \pi}{L_{e}} z\right)
\end{aligned}
$$

Where the $C_{g n}, D_{n}, C_{c n}, D_{c n}$ and $C_{2 n}$ are undetermined constants. The other coefficients are:

$$
\begin{gathered}
a_{c n}=\left[a^{2}+\left(\frac{n \pi}{L_{r}}\right)^{2}+j S \omega_{k} \mu_{2} \sigma_{2}\right]^{\frac{1}{2}} \\
D_{c n}=-\frac{\mu_{3} a_{c n} t h\left(-a_{c n} l\right)-a_{n}}{\mu_{2}\left[\operatorname{th}\left(-a_{c n} l\right)-\frac{\mu_{3}}{\mu_{2}} a_{c n}\right]} e^{-j\left(w_{k} t-a x\right)}
\end{gathered}
$$

$$
\begin{aligned}
& a_{n}=\left[a^{2}+\left(\frac{n \pi}{L_{r}}\right)^{2}+j S \omega_{k} \mu_{3} \sigma_{3}\right]^{\frac{1}{2}} \\
& \lambda_{n}=\left[a^{2}+\left(\frac{n \pi}{L_{r}}\right)^{2}\right]^{\frac{1}{2}}
\end{aligned}
$$

To confirm the undetermined constants, the following boundary and interface conations are listed as:

$$
\left\{\begin{array}{l}
\left.\frac{1}{\mu_{2}} \frac{\partial A_{2}}{\partial y}\right|_{y=g}=J_{s z} \\
\left.A_{2}\right|_{y=0}=\left.A_{3}\right|_{y=0} \\
\left.\frac{1}{\mu_{2}} \frac{\partial A_{2}}{\partial y}\right|_{y=0}=\left.\frac{1}{\mu_{3}} \frac{\partial A_{3}}{\partial y}\right|_{y=0} \\
\left.A_{3}\right|_{y=-d}=\left.A_{4}\right|_{y=-d} \\
\left.\frac{1}{\mu_{3}} \frac{\partial A_{3}}{\partial y}\right|_{y=-d}=\left.\frac{1}{\mu_{4}} \frac{\partial A_{4}}{\partial y}\right|_{y=-d}
\end{array}\right.
$$

where the $d$ is the thickness of the

sleeve.

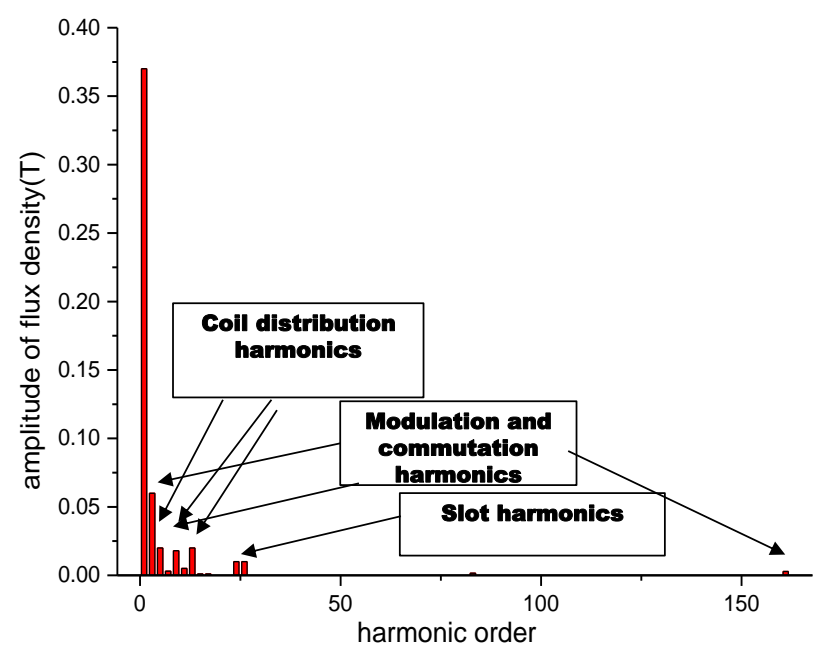

Fig. 3 the harmonic component

The harmonic components, k-th order time harmonic and the $v$-th order space harmonic, of air-gap flux density are shown in Fig.3. The distribution harmonics, mainly concentrate in $5,7,11,13^{\text {th }}$ orders, resulting in $110 \mathrm{~W}$, as the Fig.4 shows after all computation processes. Modulation harmonics mainly concentrate in $160^{\text {th }}$ order, occupying little percentage, as the same as the slot harmonics, which concentrates in 24 and $26^{\text {th }}$ orders, resulting ECL less than 
$1 \mathrm{~W}$. However, the commutation harmonics, bringing about 197W ECL, occupies the largest percentage of total ECL.

Thus, the undetermined constants can be got via (13)(17):

$$
\left\{\begin{array}{l}
C_{g n}=C_{c n}=\frac{4}{\pi} \frac{\mu_{2} J_{0, k}}{\lambda_{n}\left[\operatorname{sh} \lambda_{n} g+\frac{a_{c n}}{\lambda_{n}} D_{c n} c h \lambda_{n} g\right]} \\
D_{c n}=-\frac{\mu_{r} a_{c n} t h\left(-a_{c n} d\right)-a_{n}}{a_{n} t h\left(-a_{c n} d\right)-\mu_{4} a_{c n}} \\
D_{n}=-\frac{a_{c n}}{\lambda_{n}} \frac{\mu_{4} a_{c n} t h\left(-a_{c n} d\right)-a_{n}}{a_{n} t h\left(-a_{c n} d\right)-\mu_{4} a_{c n}} \\
C_{2 n}=\frac{4}{\pi} \frac{\mu_{2} J_{0, k} e^{a_{n} d}\left[\operatorname{ch}\left(-a_{c n} d\right)+D_{c n} \operatorname{sh}\left(-a_{c n} d\right)\right]}{\lambda_{n}\left[\operatorname{sh} \lambda_{n} g+\frac{a_{c n}}{\lambda_{n}} D_{c n} \operatorname{ch} \lambda_{n} g\right]}
\end{array}\right.
$$

Where the $\mu_{r}=\frac{\mu_{4}}{\mu_{3}}$

Substituting (18) into (10)-(12), the concrete expression of $A_{2}, A_{3}, A_{4}$ and other electromagnetic terms can be got.

For the sleeve, the axial component of the electric field intensity and the tangential component of the magnetic field intensity are the following expressions:

$$
E_{3 z}=-\frac{\partial A_{3}}{\partial t}=-j s k p \omega_{r}\left(C_{3} c h t_{3} y+D_{3} s h t_{3} y\right) e^{j\left(s k p \omega_{r} t+a x_{r}\right)}
$$

$$
H_{3 x}=\frac{1}{\mu_{3}} \frac{\partial A_{3}}{\partial y}=\frac{t_{3}}{\mu_{3}}\left(C_{3} s h t_{3} y+D_{3} c h t_{3} y\right) e^{j\left(s k p \omega_{r} t+a x_{r}\right)}
$$

where,

$$
\begin{aligned}
& C_{3}=-\frac{K_{1} \mu_{2} \mu_{3} J_{s z, k}}{\mu_{3} a K_{1} \operatorname{shag}+\mu_{2} \lambda_{3} K_{2} \operatorname{chag}} \\
& D_{3}=-\frac{K_{2} \mu_{2} \mu_{3} J_{s z, k}}{\mu_{3} a K_{1} \operatorname{shag}+\mu_{2} \lambda_{3} K_{2} \operatorname{chag}} \\
& t_{i}=\sqrt{a^{2}+j s k p w_{r} \mu_{i} \sigma_{i}} \quad(i=3,4,5)
\end{aligned}
$$

The magnet thickness depends on its equivalent electromagnetic thickness, namely the thickest depth of penetration $d_{4}$, whose expression is (30).

Thus, the expression of the ECL can be deduced by 3-d electromagnetic method from (28),

According to the complex Poynting power density method of sinusoidal magnetic field, the average power of one cycle current density vector, namely the average Poynting vector calculation formula is as the followings :

$$
S_{a v}=\frac{1}{2} \operatorname{Re}\left[\dot{E} \times \dot{H}^{*}\right]
$$

Therefore, the average power density of the closed surface $S$ is integrated to get the average electromagnetic power of the closed surface $\mathrm{S}$ :

$$
P_{a v}=\frac{1}{2} \oint_{s} \operatorname{Re}\left[\dot{E} \times \dot{H}^{*}\right] d s
$$

As long as the complex power $S_{3 d}$ has been obtained, as the (38), (39) shows:

$$
\begin{aligned}
& K_{1}=\left(\frac{\mu_{4} \lambda_{5}}{\mu_{5} \lambda_{4}} \operatorname{sh} \lambda_{4} d_{4}+\operatorname{ch} \lambda_{4} d_{4}\right) \operatorname{ch} \lambda_{3} l+\left(\frac{\mu_{3} \lambda_{5}}{\mu_{5} \lambda_{3}} \operatorname{ch} \lambda_{4} d_{4}+\frac{\mu_{3} \lambda_{4}}{\mu_{4} \lambda_{3}} \operatorname{sh} \lambda_{4} d_{4}\right) \operatorname{sh} \lambda_{3} l \\
& K_{2}=\left(\frac{\mu_{4} \lambda_{5}}{\mu_{5} \lambda_{4}} \operatorname{sh} \lambda_{4} d_{4}+\operatorname{ch} \lambda_{4} d_{4}\right) \operatorname{sh} \lambda_{3} l+\left(\frac{\mu_{3} \lambda_{5}}{\mu_{5} \lambda_{3}} \operatorname{ch} \lambda_{4} d_{4}+\frac{\mu_{3} \lambda_{4}}{\mu_{4} \lambda_{3}} \operatorname{sh} \lambda_{4} d_{4}\right) \operatorname{ch} \lambda_{3} l \\
& S_{r 3 d}=\sum_{k, n} S_{\mathrm{r}, \mathrm{n}, k}=\pi D_{r} L_{r} \sum_{k} \sum_{n} \frac{4 j S \omega_{1} \mu_{g} J_{0, k}^{2} a_{2} D_{c n} e^{2 j\left(w_{k} t-a x\right)}}{(n \pi a)^{2}\left[\operatorname{sh} \lambda_{n} g+\frac{a_{c n} D_{c n}}{\lambda_{n}} \operatorname{ch} \lambda_{n} g\right]\left[\operatorname{sh} \lambda_{n} g+\frac{a_{c n} D_{c n}}{\lambda_{n}} e^{2 j\left(w_{k} t-a x\right)} \operatorname{ch} \lambda_{n} g\right]} \\
& S_{r 2 d}=\pi D_{r} L_{r} \sum_{k} \frac{j S \omega_{1} \mu_{g} J_{0, k}^{2} \xi_{c} D_{c} e^{2 j\left(w_{k} t-a x\right)}}{2 a^{2}\left[\operatorname{shag}+\frac{\xi_{c} D_{c}}{a} \operatorname{chag}\right]\left[\operatorname{shag}+\frac{\xi_{c} D_{c}}{a} e^{2 j\left(w_{k} t-a x\right)} \operatorname{chag}\right]}
\end{aligned}
$$

where

$$
d_{4}=\frac{1}{\sqrt{\pi f_{0} \mu_{4} \sigma_{4}}}
$$

The ECL caused by end of winding could be calculated by subtracting $P_{r 2 d}$ from $P_{r 3 d}$, which can be got from integrating by $S_{r 2 d}$ and $S_{r 3 d}$, reaching about $24 \mathrm{~W}$ showing in Fig.4

$$
\left\{\begin{array}{l}
\xi_{c}=\left(a^{2}+j S \omega_{k} \mu_{2} \sigma_{2}\right)^{\frac{1}{2}} \\
\xi=\left(a^{2}+j S \omega_{k} \mu_{3} \sigma_{3}\right)^{\frac{1}{2}} \\
D_{c}=\frac{\mu_{3} \xi_{c} t h\left(-l \xi_{c}\right)-\xi}{\mu_{2} t h\left(-l \xi_{c}\right)-\frac{\mu_{3}}{\mu_{2}} \xi_{c}}
\end{array}\right.
$$




$$
p_{r}=\frac{s k p^{2} \omega_{r} \tau L_{a}}{\mu_{3}} \operatorname{Re}\left(j C_{3} D_{3}^{*} t_{3}^{*}\right)
$$

Here, in order to get the end-effect factor, the 2-d formation of (29) and (31) are calculated in two-dimensional electromagnetic field, the similar expression of ECL by 2-d electromagnetic equation can be deduced, afterwards, the total rotor eddy current losses generated by motor can be got, and the difference between it and the one of the motor section calculated by subtraction between them, is just the eddy current loss of the winding end. When $2 \mathrm{~d}$ electromagnetic field equation is utilized, the expression of the total complex power coming into the rotor surface is listed as formula (29). Besides, the compare of the $2 \mathrm{~d}$ and $3 \mathrm{~d}$ calculation results are shown in Fig.24.

The varieties of flux density harmonic component in airgap that penetrate into the whole surface of the rotor, generating corresponding ECL $P_{k}$, show in Fig.4

For the permanent magnet, the axial component of the electric field intensity and the tangential component of the magnetic field intensity are the following expressions:

$$
\begin{aligned}
& E_{4 z}=-\frac{\partial A_{4}}{\partial t}=-j s k p \omega_{r}\left(C_{4} c h t_{4} y+D_{4} s h t_{4} y\right) e^{j\left(s k p \omega_{r} t+a x_{r}\right)} \\
& H_{4 x}=\frac{1}{\mu_{4}} \frac{\partial A_{4}}{\partial y}=\frac{t_{4}}{\mu_{4}}\left(C_{4} s h t_{4} y+D_{4} c h t_{4} y\right) e^{j\left(s k p \omega_{r} t+a x_{r}\right)}
\end{aligned}
$$

Thus, the Poynting vector that penetrate into the magnet is:

$$
\begin{aligned}
& S_{4}=\frac{1}{2} \operatorname{Re}\left[\left.\left.\dot{E_{4 z}}\right|_{y=-l} \cdot \dot{H}_{4 x}^{*}\right|_{y=-l}\right]=-\frac{s k p \omega_{r}}{2 \mu_{4}} \times \\
& \operatorname{Re}\left[j t_{4}^{*}\left(C_{4} c h t_{4} l-D_{4} s h t_{4} l\right)\left(D_{4} c h t_{4} l-C_{4} s h t_{4} l\right)^{*}\right]
\end{aligned}
$$

So, the corresponding average electromagnetic power is:

$P_{m}=-\frac{s k p^{2} \omega_{r} \tau L_{a}}{\mu_{3}} \operatorname{Re}\left[j t_{4}^{*}\left(C_{4} c h t_{4} l-D_{4} s h t_{4} l\right)\left(D_{4} c h t_{4} l-C_{4} s h t_{4} l\right)^{*}\right]$

So, the average electromagnetic power generated in sleeve is:

$$
p_{s}=p_{r}-p_{m}
$$

The total ECL in sleeve is:

$$
\begin{aligned}
& P_{\text {sleeve }}=\sum_{k, v} p_{s} \\
& P_{\text {mag }}=\sum_{k, v} p_{m}
\end{aligned}
$$

Similarly, the $P_{r}$ in permanent magnet can also be deduced from the recurrence relation described as the above process accounting for the recurrence relation(15), (16) and solution(21) and (22) can still be applied in permanent magnet. The total loss result is listed in Fig.24 .

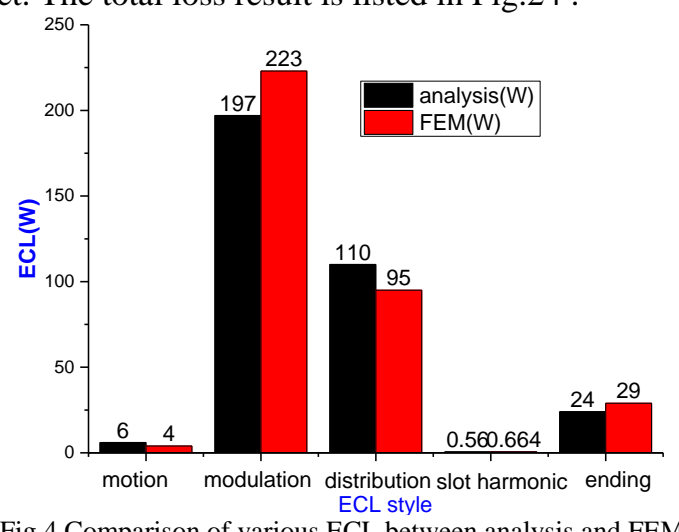

Fig.4 Comparison of various ECL between analysis and FEM

\section{THE MULTI-OBJECTIVE OPTIMIZATION(MOO) OF THE ECL}

Considering the different position, conductivity, temperature capability and the failure criteria, the different optimization weighting factor should be given to permanent magnet and the sleeve. A MOO method, which make use of the utilization method to limite the ECL here, accounting for those considerations can be adopted. The objective function can be expressed as:

$$
\left\{\begin{array}{l}
F_{1}(X)=\omega_{1} P_{\text {sleve }} \\
F_{2}(X)=\omega_{2} P_{\text {mag }}
\end{array}\right.
$$

The convergence evaluation function is listed as:

$$
F(X)=F_{1}(X)+F_{2}(X)
$$

Here we use the utilization method from [25]-[28]. The $\omega_{1}$ and $\omega_{2}$ form the utilization vector which ensures the optimization margin and constraints of every objective.

The optimization variables, listed in TABLE 2, are mainly from the structure parameters of the rotor, while the ones of the stator as the constrain, including the temperature limitation, via the air gap to contact with the ones of the rotor.

The constraints are:

1 , The permanent magnet maximum demagnetizing working point under load condition should be guaranteed over the inflection point of the demagnetization curve:

The maximum demagnetization magnetic motive force of direct axis per-unit value $f_{a d}$ is:

$f_{a d}=\frac{2 F_{a d}}{F_{c} \sigma_{0}}=\frac{2}{F_{c} \sigma_{0}} \cdot \frac{1.35 K_{d p} N K_{a d}}{p} I_{h}=\frac{2.7 K_{d p} N}{\sigma_{0} p F_{c}} K_{a d} I_{h}$

where the maximum demagnetization current of direct axis $I_{h}$ is :

$I_{h}=\frac{E_{0} X_{d}+\sqrt{E_{0}^{2} X_{d}^{2}-\left(R_{1}^{2}+X_{d}^{2}\right)\left(E_{0}^{2}+U^{2}\right)}}{R_{1}^{2}+X_{d}^{2}}$

Based on equivalent magnetic circuit computation, when $I_{h}$ is injected in coils, the working point under load condition is: $\left\{\begin{array}{l}\varphi_{m n}=\frac{\lambda\left(1-\mathrm{f}_{a d}\right)}{\lambda_{n}-1}=b_{m n} \\ f_{m n}=\frac{1+\lambda_{n} f_{a d}}{\lambda_{n}+1}=h_{m n}\end{array}\right.$

Thus, the maximum demagnetization working point of permanent magnet is $\left(b_{m n}, h_{m n}\right)$, satisfying the constraint:

$\left\{\begin{array}{l}b_{m n}>b_{k} \\ h_{m n}<h_{k}\end{array}\right.$

2 , The maximum temperature of each part among the motor should be below the allowable temperature with permitted allowance reserved.

$\{\Delta T\}+\left\{T_{0}\right\}<\left\{T_{\max }\right\}=\left\{\max \left(\mathrm{T}_{\text {coil }}, \mathrm{T}_{\text {mag }}, \mathrm{T}_{\text {sleve }}\right)\right\}$

where the $\mathrm{T}_{\text {coil }}, \mathrm{T}_{\text {mag }}, \mathrm{T}_{\text {sensor }}$ are temperature of coils, magnet and its sleeve respectively. The temperature distribution can be got via the hierarchical model by the right model in Fig.1 via the following expression: 


$$
\Delta T=\frac{\Delta \psi}{A h}
$$

where $\Delta \psi$ is heat flux; $\mathrm{A}$ is area of dissipation; $\mathrm{h}$ is equivalent coefficient of heat conductivity or dissipation.

The heat source in every layer is the eddy current loss $p_{n}$ in every layer. Thus, the maximum temperature increase of the original HSPMSM model, calculated by equivalent thermal network method as Fig.5 shows, exists the outer surface of the sleeve, $96 \mathrm{~K}$.

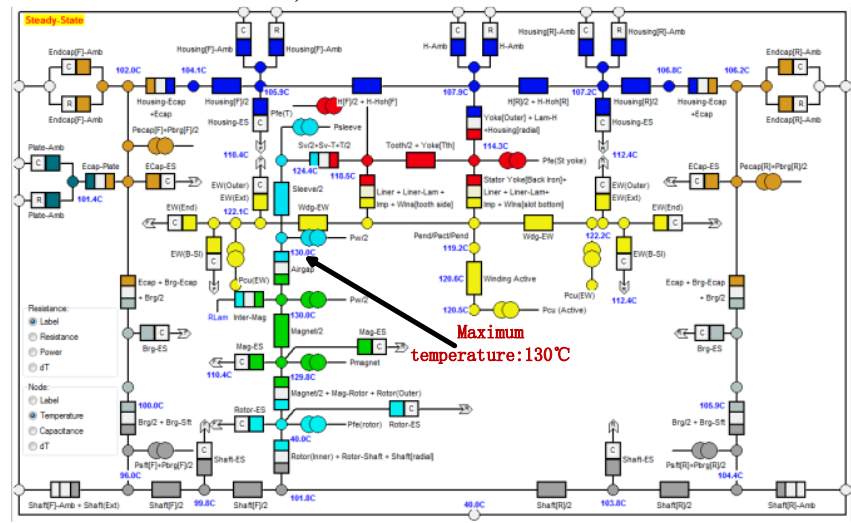

Fig.5 Equivalent thermal network node graph (steady state)

3, Strength constraint of rotor sleeve:

The Von-Mises stress of sleeve $\sigma_{v m}^{h}$ is:

$\sigma_{v m}^{h}=\sqrt{\frac{1}{2}\left[\left(\sigma_{r m}-\sigma_{\theta m}\right)^{2}+\left(\sigma_{r m}\right)^{2}+\left(\sigma_{\theta m}\right)^{2}\right]}$

which should satisfy the constraint:

$\sigma_{v m}^{h}<\frac{\sigma_{\max }^{h}}{n}$

where $\sigma_{r m}, \sigma_{\theta m}$ are radial and tangential equivalent stress respectively; the $\sigma_{\max }^{h}=1146 M p a$ is allowable limit of GH4169, the material of sleeve, with $n=1.3$, the safety coefficient.

4, Electric load constraint of winding:

$A=\frac{m N I_{1} K_{d p}}{p \tau_{1}} \leq A_{0}$

Where $A_{0}=7 \times 10^{5} \mathrm{~A} / \mathrm{m}$, the allowable limit of electric load with some allowance reserved.

5, Thermal constraint of winding:

$A J_{1} \leq\left. A J_{1}\right|_{0}$

$$
J_{1}=\frac{I_{1}}{a \pi\left[N_{t 1}\left(\frac{d_{11}}{2}\right)^{2}+N_{t 2}\left(\frac{d_{12}}{2}\right)^{2}\right]}=\frac{I_{1}}{2 a \pi N_{t}\left(\frac{d}{2}\right)^{2}}
$$

where $a$ is number of parallel branches; $N_{t}$ is number of wires per conductor; $d$ is diameter of wire with its insulation.

$\left.A J_{1}\right|_{0}=650 A^{2} / \mathrm{mm}^{3}$, the allowable limit of thermal load.

6, Constraint of spacer factor:
$k_{c}=\frac{N_{t} \times n_{c} \times d^{2}}{S_{a}-S_{j}} \times 100 \%$

where $n_{c}$ is number of conductors per slot; $S_{a}$ is area of slot; $S_{j}$ is area of slot insulation. According to the actual local level of wire assembly process of motor and the motor cooling requirements, the $k_{c}<70 \%$ constraint.

7 , length constraint of winding end:

$$
\begin{aligned}
& L_{E}=2\left(d+l_{e}^{\prime}\right) \\
& l_{e}^{\prime}=\frac{\tau_{y}}{2 \cos \alpha_{0}} \\
& f_{d}=l_{e}^{\prime} \sin \alpha_{0} \\
& \tau_{y}=\frac{\pi\left(D_{i 1}+2 h_{s 0}+2 h_{s 1}+h_{s 2}+\frac{b_{s 2}}{2}\right) \beta}{2}
\end{aligned}
$$

$l_{E}<l_{\max }$, where the $l_{\max }=110 \mathrm{~mm}$, the limit length of ending depends on the HSPMSM assembly.

8, length constraint of electromagnetic air-gap:

Here, with consideration of the cylindrical shape of the magnet, the air-gap flux density can be deduced by the following expression:

$$
\begin{aligned}
& B_{\delta}=\frac{\mu_{0} M R}{2 N} \sum_{n=0}^{N} \sum_{k=1}^{2} S(n) \cos \left(\theta^{\prime}(n)\right)\left[r-R \cos \left(\theta-\theta^{\prime}(n)\right)\right] \times \\
& I\left(r, \theta, z ; R, \theta^{\prime}(n), z_{k}\right)
\end{aligned}
$$

which will be calculated in radial and circumferential direction respectively to get the total number.

$T_{e m \max }=\sqrt{2 \pi} B_{\delta 1} L_{e f} R_{s}^{2} A \times 10^{-4}$

$R_{s}=\sqrt{\frac{2 \sqrt{2} p t_{b} B_{\delta 1} A}{\omega_{b} \rho_{F e} \times 10^{-3}}}$

Thus, the electromagnetic air-gap $\delta_{e}$ satisfy the constraint:

$\delta_{e}=R_{s}-R_{m}>R_{h}-R_{m}>0$

9, length constraint of mechanical air-gap $\delta_{m}$ :

$\delta_{e}>\delta_{m}=R_{s}-R_{h}>0$

(62)

10 , Other geometric constraints

Thus, the constraint conditions in form of penalty function is used to construct the augmented objective function, which uses outer point method, the nonlinear constrained optimization problem is transformed into an unconstrained optimization problem with polynomial penalty function, in which the $g_{i}(\mathrm{x})$ is constraint, $u_{i}\left(\mathrm{~g}_{i}\right)$ is unit step function, $r^{(k)}$ is penalty factor, which satisfy the following condition:

$0<r_{1}<r_{2} \ldots<r_{k}<r_{k+1} \ldots$, the argumented objective function is:

$F_{i}\left[X, \mathrm{r}^{(\mathrm{k})}\right]=\mathrm{F}_{i}(X)+\mathrm{r}^{(\mathrm{k})} \sum_{i=1}^{m}\left[\mathrm{~g}_{i}(X)\right]^{2} u_{i}\left(\mathrm{~g}_{i}\right)$ 
The unit step function $u_{i}\left(\mathrm{~g}_{i}\right)$ is: $u_{i}\left(\mathrm{~g}_{i}\right)= \begin{cases}0, & \text { if } \mathrm{g}_{i}(\mathrm{x}) \leq 0, \text { constraint is satisfied } \\ 1, & \text { if } \mathrm{g}_{i}(\mathrm{x})>0, \text { constraint is not satisfied }\end{cases}$

The optimization progress adopting above method by chaotic particle swarm optimization is illustrated as Fig.6.

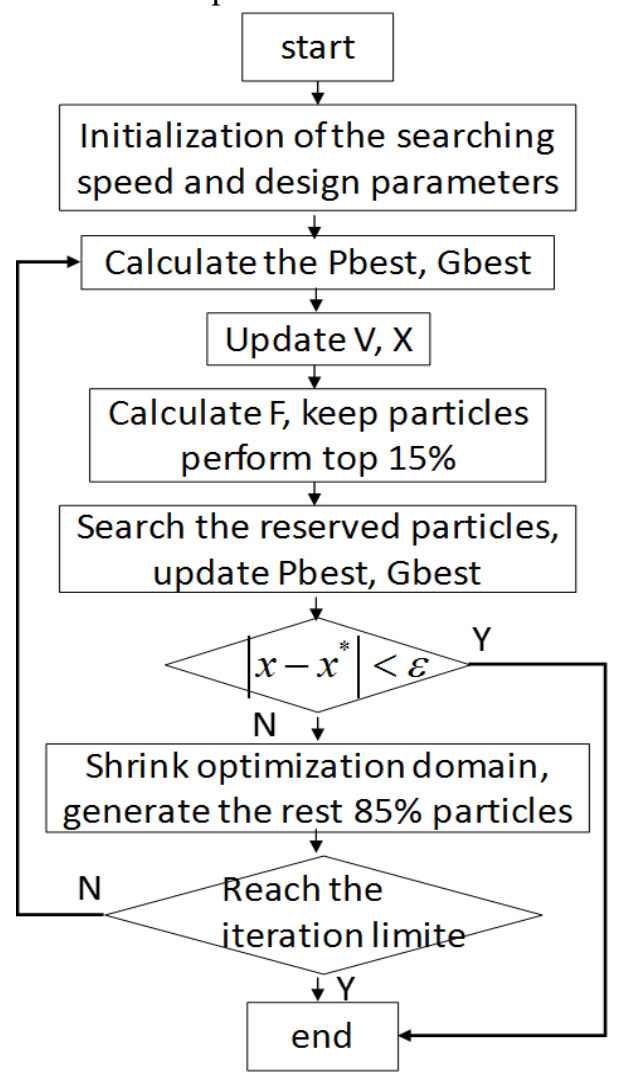

Fig.6 the optimization progress

Chaotic particle swarm algorithm calculation process is shown in the Fig, the specific operation process is as follows:

1.Random initialization of the particle swarm: set the reliable population size, the initial position of the particle and the initial velocity, inertia factor and other parameters

2.Evaluate and compute the current adaptation value of every particle; the position and the adaptive value of each particle are stored in the pbest of each particle, and the position and the adaptive value of the optimal individual in all pbest are stored in the gbest.

3. Update the current velocity and position of the particle according to the velocity and position function, the speed and position function is as follows:

$v_{i, j}(t+1)=w v_{i, j}(t+1)+c_{1} r_{1}\left[p_{i, j}-x_{i, j}(t)\right]+c_{2} r_{2}\left[p_{\mathrm{g}, j}-x_{i, j}(t)\right]$

$x_{i, j}(t+1)=x_{i, j}(t)+v_{i, j}(t+1), j=1,2, \ldots, d$

where weights $\mathrm{w}$ update under the following type adaptively:

$w=\left\{\begin{array}{l}w_{\text {min }}-\frac{\left(w_{\text {max }}-w_{\text {min }}\right)\left(f-f_{\text {min }}\right)}{\left(f_{\text {avg }}-f_{\text {min }}\right)}, f \leq f_{\text {avg }} \\ w_{\text {max }}, f>f_{\text {avg }}\end{array}\right.$

4.Calculate the objective function value of each particle, and then retain the best performance of the $15 \%$ particles in the group

5.In the population, the best particle in the swarm is searched, and the pbest and population of gbest are updated. The search procedure is as follows:

(1) make $\mathrm{k}=0$, The decision variables $x_{j}^{k}, j=1,2, \ldots n$ are mapped into chaotic variables $s_{j}^{k}$ varying in [0,1] :

$s_{j}^{k}=\frac{x_{j}^{k}-x_{\min , j}}{x_{j}^{k}-x_{\max , j}}, j=1,2, \ldots n$

Where $x_{\max , j}$ and $x_{\min , j}$ are the lower and upper bounds for the $\mathrm{j}$-th dimensional Searching variable respectively.

(2) Calculation of chaotic variables for the next iteration: $s_{j}^{k+1}=4 s_{j}^{k}\left(1-s_{j}^{k}\right), j=1,2, \ldots n$

(3) Transform chaotic variable $s_{j}^{k+1}$ into design variable:

$x_{j}^{k+1}=x_{\min , j}+s_{j}^{k+1}\left(x_{\max , j}-x_{\min , j}\right), j=1,2, \ldots \mathrm{n}$

(4)Evaluate new solution according to design variable $x_{j}^{k+1}$ : If new solution is better than initial solution which is $X^{(0)}=\left[x_{1}^{(0)}, x_{2}^{(0)} \ldots x_{n}^{(0)}\right]$ or the steps of chaotic searching progress reach top limitation of the iteration, set new solution as the result of chaotic searching progress, otherwise, change to $\operatorname{step}(2)$.

6 . If the stop condition (preset convergence precision and maximum number of iterations) is satisfied, the searching progress stops and output results, otherwise, change to step 7.Contract search area under according to the followings:

$\mathrm{x}_{\min , j}=\max \left\{x_{\min , j}, x_{g, j}-r\left(x_{\max , j}-x_{\min , j}\right)\right\}, 0<r<1$

$\mathrm{x}_{\max , j}=\min \left\{x_{\max , j}, x_{g, j}+r\left(x_{\max , j}-x_{\min , j}\right)\right\}, 0<r<1$

Where $x_{g, j}$ represents the $\mathrm{j}$-th dimensional design variable.

8. Compute the evaluation function $\mathrm{F}(\mathrm{x})$; if the expression $\left|F^{k+1}(x)-F^{k}(x)\right|<\varepsilon^{f}$ is satisfied, iterations can be jumped as convergence.

9. The remaining $85 \%$ of the particles are randomly generated within the space of contraction.

After MOO optimization, the optimal design variables are listed as the following TABLE

Design parameters that exists in the design vector $\mathrm{X}$ is listed in TABLE 1 as the following form:

\begin{tabular}{|c|c|c|c|}
\hline \multirow{2}{*}{ Motor parameter } & \multirow{2}{*}{$\begin{array}{c}\text { Design } \\
\text { variable }\end{array}$} & \multicolumn{2}{|c|}{ Design value } \\
\hline & & Original & optimal \\
\hline $\begin{array}{l}\text { Rated power } \\
(\mathrm{kW})\end{array}$ & & 30 & 30 \\
\hline $\begin{array}{c}\text { Rated voltage } \\
\text { (V) }\end{array}$ & & $480 \mathrm{dc}$ & 480 \\
\hline Rated speed & & $48000 \mathrm{r} / \mathrm{min}$ & $48000 \mathrm{r} / \mathrm{min}$ \\
\hline Polar numbers & & 2 & 2 \\
\hline Slot numbers & & 24 & 24 \\
\hline $\begin{array}{l}\text { Outer radius of } \\
\text { stator }(\mathrm{mm})\end{array}$ & $x_{1}$ & 150 & 178 \\
\hline $\begin{array}{l}\text { Inner radius of } \\
\text { stator }(\mathrm{mm})\end{array}$ & $x_{2}$ & 62 & 67.6 \\
\hline $\begin{array}{l}\text { Stator length } \\
(\mathrm{mm})\end{array}$ & $x_{3}$ & 60 & 60 \\
\hline $\begin{array}{c}\text { Lamination factor } \\
\text { of stator }\end{array}$ & & 0.95 & 0.95 \\
\hline Stator material & & 20WTG1500 & $\begin{array}{c}\text { 20WTG150 } \\
0 \\
\end{array}$ \\
\hline
\end{tabular}




\begin{tabular}{|c|c|c|c|}
\hline 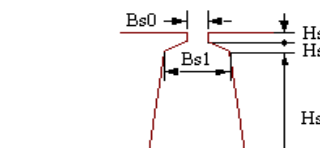 & slot $\mathrm{s}$ & & \\
\hline $\begin{array}{c}\text { Slot notch height Hs0 } \\
(\mathrm{mm})\end{array}$ & & 0.5 & 0.5 \\
\hline $\begin{array}{c}\text { Slot shoulder height } \\
\text { Hs1 }(\mathrm{mm})\end{array}$ & & 0.6 & 0.6 \\
\hline Slot body height Hs2 (mm) & $x_{4}$ & 20 & 24 \\
\hline Slot notch width Bs0(mm) & $x_{5}$ & 2 & 1.86 \\
\hline Slot upper width Bs1(mm) & $x_{6}$ & 4.9 & 5.6 \\
\hline $\begin{array}{l}\text { Slot bottom width } \\
\text { Bs2(mm) }\end{array}$ & $x_{7}$ & 10.2 & 11.34 \\
\hline Rotor outer radius $(\mathrm{mm})$ & $x_{8}$ & 55 & 59 \\
\hline Sleeve outer radius $(\mathrm{mm})$ & $x_{9}$ & 55 & 59 \\
\hline Sleeve thickness (mm) & $x_{10}$ & 5 & 6.5 \\
\hline Magnet outer radius (mm) & $x_{11}$ & 45 & 46 \\
\hline Magnet axial length(mm) & $x_{12}$ & 60 & 60 \\
\hline Sleeve material & & GH4169 & GH4169 \\
\hline Magnet thickness (mm) & & solid & solid \\
\hline Remanence $(\mathrm{T})$ & & 1.05 & 1.05 \\
\hline $\begin{array}{l}\text { Connection mode of } \\
\text { winding }\end{array}$ & & $\mathrm{Y}$ & $\mathrm{Y}$ \\
\hline $\begin{array}{c}\text { Number of parallel } \\
\text { branches }\end{array}$ & & 2 & 2 \\
\hline Pitch & & 12 & 12 \\
\hline Conductor diameter $(\mathrm{mm})$ & & 0.8 & 0.8 \\
\hline insulation thickness $(\mathrm{mm})$ & & 0.06 & 0.06 \\
\hline $\begin{array}{l}\text { Number of conductor per } \\
\text { slot }\end{array}$ & & 12 & 10 \\
\hline $\begin{array}{c}\text { Number of wires per } \\
\text { conductor }\end{array}$ & & 8 & 10 \\
\hline $\begin{array}{c}\text { Slot insulation thickness } \\
(\mathrm{mm})\end{array}$ & & 0.35 & 0.35 \\
\hline $\begin{array}{l}\text { Layer insulation thickness } \\
(\mathrm{mm})\end{array}$ & & 0.35 & 0.35 \\
\hline Slot full rate(\%) & & 41 & 42 \\
\hline Insulation grade & & $\mathrm{H}$ & $\mathrm{H}$ \\
\hline $\begin{array}{l}\text { Axial length of the } \\
\text { winding end }(\mathrm{mm})\end{array}$ & & $50 、 60$ & 49,58 \\
\hline
\end{tabular}

The optimization performance is listed as the followings:

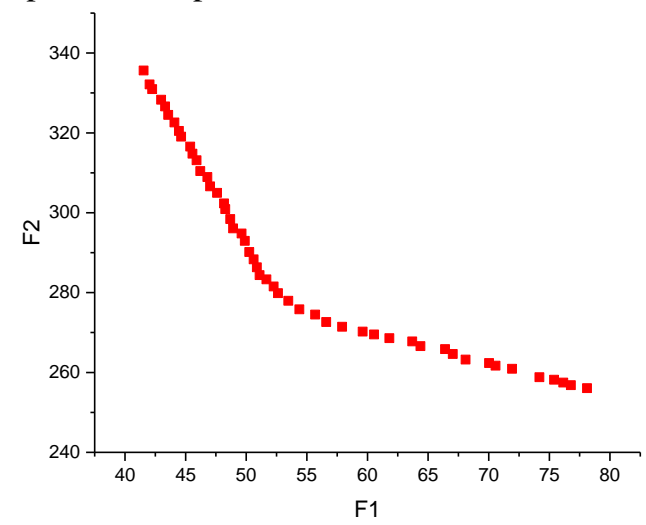

Fig.7 Pareto Front

The optimization point $(258,77)$ is selected from Pareto Front as Fig.7 shows, accounting for other constraints requirements such as the strength, geometric and temperature increase.

The evaluation function converges after 51 iterations as Fig. 8 shows. The ECL increase first, due to increase of the reluctance of air-gap, then decrease as the air-gap increase, resulting from the increase of coil current gaining the upper hand, with air-gap continued increase, as Fig.9 shows.

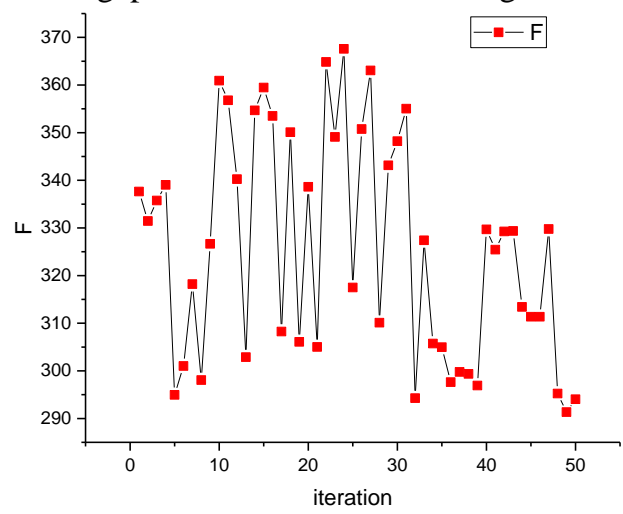

Fig. 8 Convergence curve of convergence evaluation function

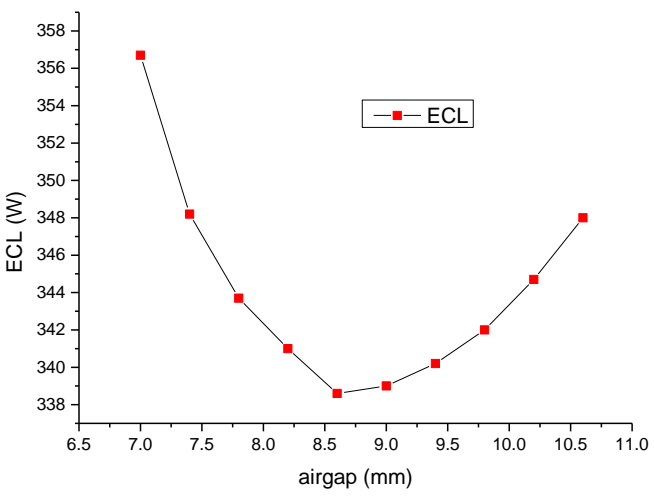

Fig.9 ECL varying with air-gap

The ECL increase as the slot width increase, owing to more high order harmonics penetrating into the rotor from slot, as Fig.10 shows.

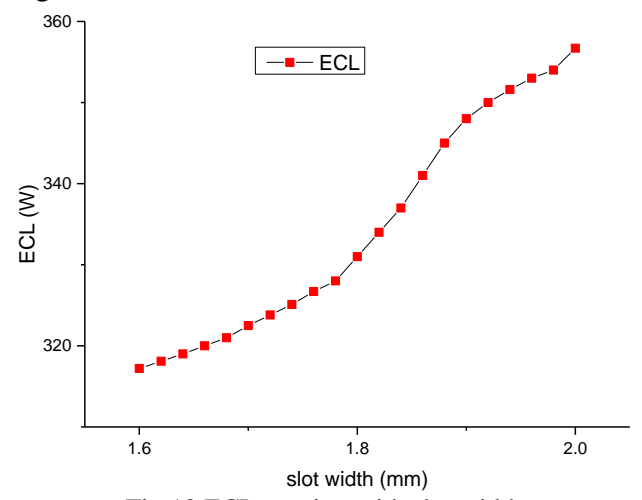

Fig.10 ECL varying with slot width

The sleeve plays the role of shield, of which the thickness increase leading to the ECL decrease of magnet, while, that increase of sleeve gains the upper hand as the sleeve thickness increase over $6.5 \mathrm{~mm}$.

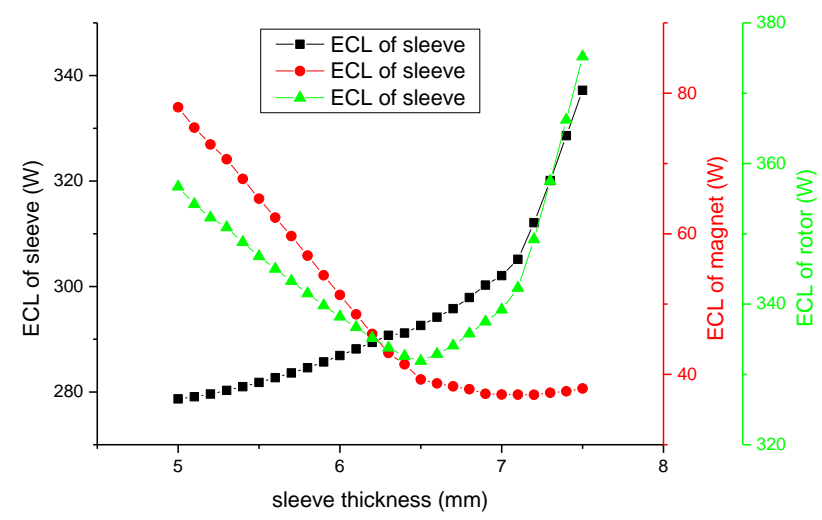

Fig.11 ECL in sleeve and permanent magnet varying with sleeve thickness 


\section{RESULTS VALIDATION VIA FEM}

Here the finite element method(FEM) is used to validate the computation results got from above method.

First, the electromagnetic optimization results are validated by FEM. The control equation in eddy current generation field is:

$$
\left\{\begin{array}{l}
\nabla \times v(\nabla \times A)=-\sigma\left(\nabla \phi+\frac{\partial A}{\partial t}-V \times \nabla \times A\right) \\
\nabla \cdot\left[\sigma\left(\nabla \phi+\frac{\partial A}{\partial t}\right)\right]=0
\end{array}\right.
$$

The equivalent variation expression is:

$\left\{\begin{array}{l}\delta F\{A\}=\iiint_{\Omega}(v \nabla \times A) \cdot(\nabla \times \delta A) d \Omega+\frac{\partial}{\partial t} \sigma \iiint_{\Omega} A \cdot \delta A d \Omega \\ A=A_{0}\end{array}\right.$

With proper boundary condition exerted in FEM model, the eddy current loss in total rotor of the original model is computed as $356.7 \mathrm{~W}$ approximately as the Fig. 12 shows:
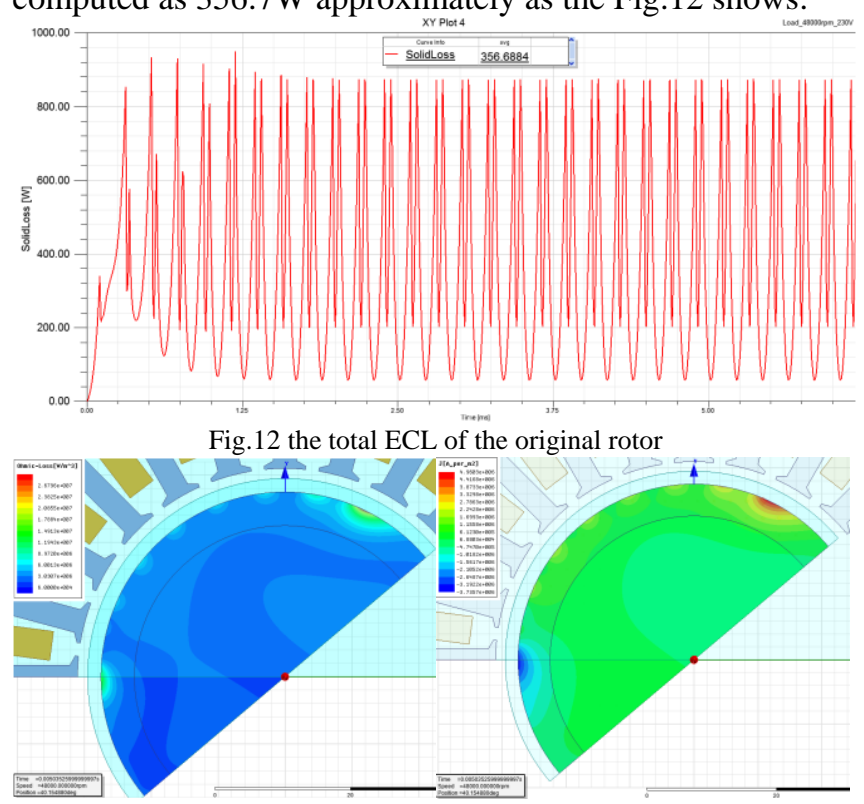

(a)the ECL

(b) the ECL density

Fig. 13 the ECL and the ECL density

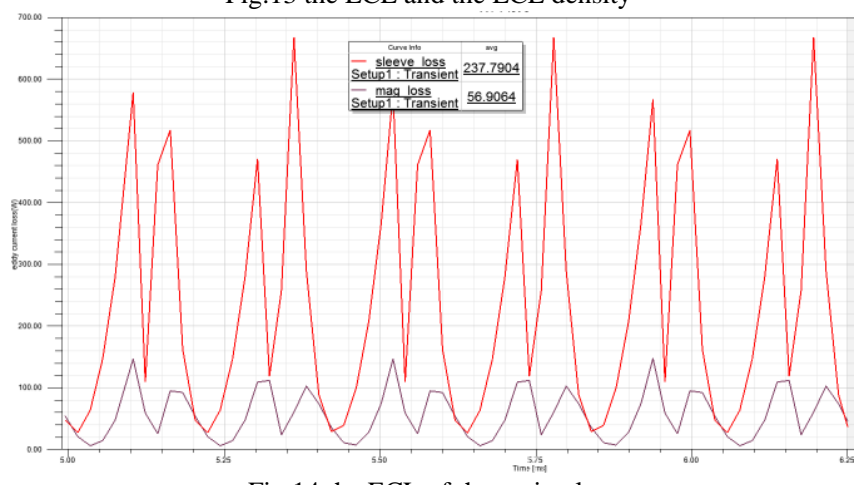

Fig.14 the ECL of the optimal rotor

The total ECL of the optimal rotor is $294 \mathrm{~W}$, calculated by FEM, consisting of ECL in sleeve $237 \mathrm{~W}$ and in permanent magnet $56.9 \mathrm{~W}$ respectively, as Fig.14 shows, which has $12 \%$ error with the analysis results $335 \mathrm{~W}$.

Second, the thermal optimization results are examined by FEM as illustrated as the followings:

FEM process of three dimensional steady thermal field and fluid field of this PMSM deserves fundamentals of heat transfer, namely, with regard to analyzation of steady thermal field, steady heat conduction equation does not contain the time term, meanwhile, including heat source and medium, which can be expressed under the Cartesian coordinate system as the shown below:

$$
\begin{cases}\frac{\partial}{\partial x}\left(k_{x} \frac{\partial T}{\partial x}\right)+\frac{\partial}{\partial y}\left(k_{y} \frac{\partial T}{\partial y}\right)+\frac{\partial}{\partial z}\left(k_{z} \frac{\partial T}{\partial z}\right)=-q, & (x, y, z) \in \Omega \\ \frac{\partial T}{\partial n}=0 & (x, y, z) \in \text { Adiabatic Surface } \\ -k \frac{\partial T}{\partial n}=\alpha\left(T-T_{f}\right) & (x, y, z) \in \text { Radiating Surface }\end{cases}
$$

Where, $\mathrm{T}$ is temperature to be solved; $K\left(k_{x}, k_{y}, k_{z}\right)$ is thermal conductivity along each direction, $\mathrm{W} /(\mathrm{m} . \mathrm{K}) ; \mathrm{q}$ is volume density summary of each heat source existing in solution domain, $W / \mathrm{m}^{3} ; \alpha$ is surface coefficient of heat transfer, $W /\left(\mathrm{m}^{2} \cdot \mathrm{K}\right) ; T_{f}$ is the temperature of fluid around heat surface, $\mathrm{K}$.

The fluid flow is governed by the laws of physical conservation, accounting for the fundamentals of fluid dynamics and heat transfer, the principle of mass, momentum and energy conservation are satisfied in the motor.When the fluid in motor is incompressible and flowing steadily, the corresponding three dimensional governing equations can be simplified as:

$$
\operatorname{div}(\rho u \phi)=\operatorname{div}(\Gamma \operatorname{grad} \phi)+S
$$

Where, $\phi$ is general variable, $\rho$ is the density fo fluid, $\mathrm{kg} / \mathrm{m}^{3} ; \Gamma$ is spreading coefficient; $\mathrm{S}$ is the source term.

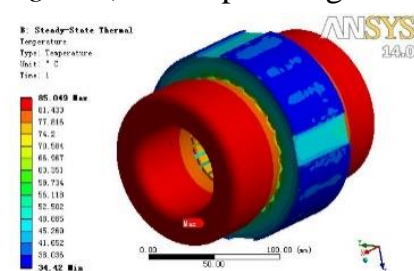

(a)the temperature of rotor

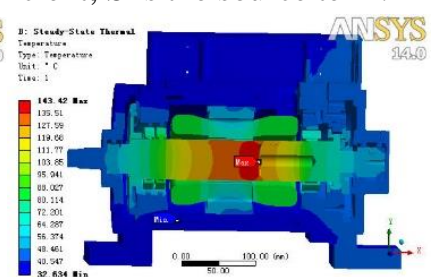

(b) the temperature of motor Fig. 15 the temperature of the motor

The highest temperature is $142{ }^{\circ} \mathrm{C}$ located in the positive center in cylindrical permanent magnet as Fig.15(a) shows. The biggest strength reached $478 \mathrm{Mpa}$, satisfying the strength constraint of sleeve commendably, at the interface between between sleeve and permanent magnet showing in Fig.16(a).

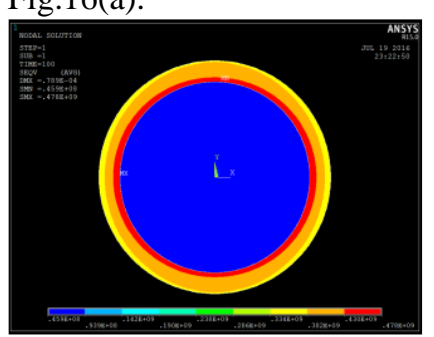

(a) strength

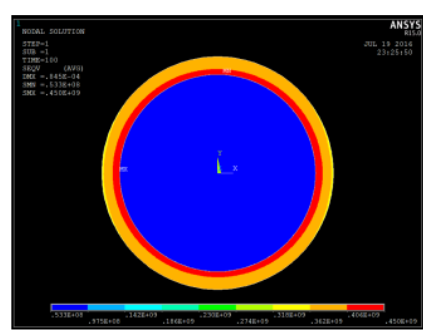

(b) strain
Fig.16 the strength and strain of the rotor

The prototype of this 30kw HSPMSM(Fig.17(a)) after optimization has been manufactured, with its controller and driver(Fig.17(b)) is shown as the followings: 


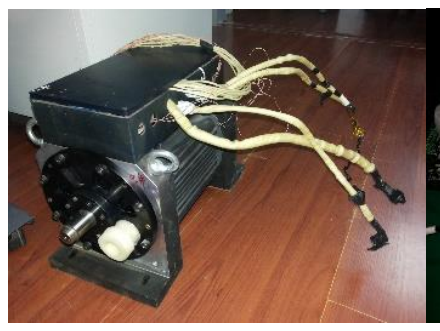

(a) the prototype

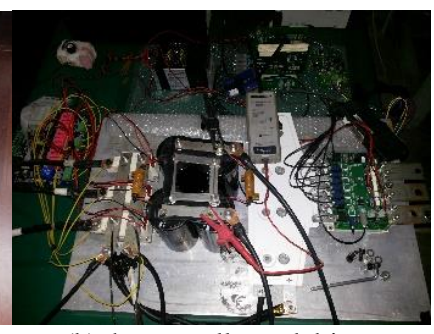

(b) the controller and driver
Fig. 17 the prototype and its controller

\section{EXPERIMENT}

The motor prototype is designed in the laboratory, and its electromagnetic losses are expressed in the form of heat, therefore, the total electromagnetic loss of the motor is equal to the heat generated by the motor excluding the windage loss in the unit time.

The total input power of the motor that the total input electromagnetic power of the motor $p_{\text {in }}$ can be tested by power analyzer WT3000. The electromagnetic loss of the motor $p_{e}$ can be calculated as the followings:

$$
p_{e}=p_{\text {in }}-p_{f}
$$

The $p_{f}$ is windage loss, which can be tested by draging test showing in Fig.18
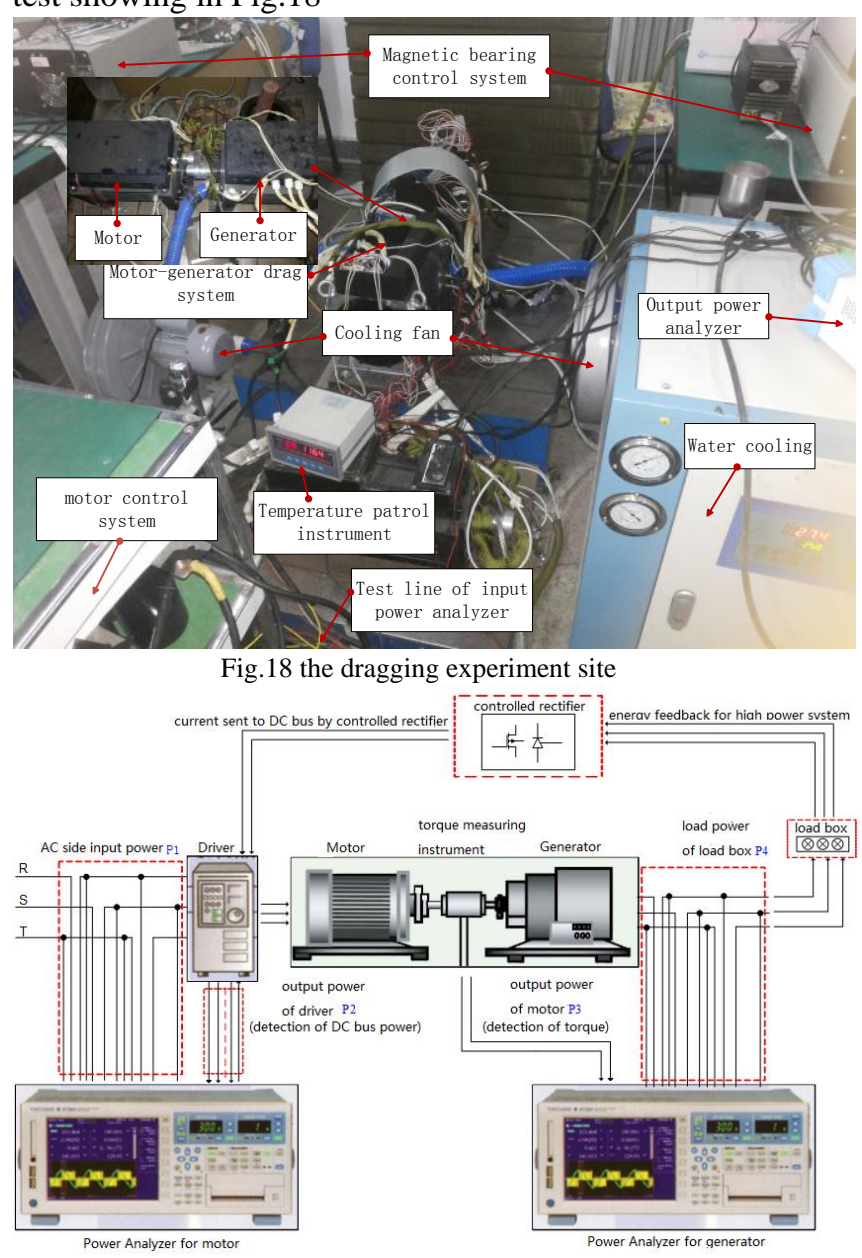

Fig.19 the sketch of the drag system

First, when the motor reach the rated speed

The electromagnetic loss of stator consist of the core loss and the winding loss in which the effect of AC resistence should be considered, with the LCR analyzer as the Fig. 22 shows its testing.

With the difference of loss component between the motor and the generator, the power composition of them is:

$$
\begin{aligned}
& p_{m}=p_{w}+p_{f e}^{m}+p_{e}^{m}+p_{g} \\
& p_{g}=p_{w}+p_{f e}^{g}+p_{e}^{g}+p_{l}
\end{aligned}
$$

In equation (78), $p_{m}$ is the input power of motor, measured by power analyzer(Fig.24(a)). $p_{w}$ is the windage loss considering be the same value in both motor and generator owing to the same speed of them, $p_{f e}^{m}$ is the core loss of the motor, $p_{e}^{m}$ is the eddy current loss of the motor. In equation (79), $p_{g}$ is the input power of the generator, $p_{f e}^{g}$ and $p_{e}^{g}$ are core loss and eddy current loss of the generator respectively, $p_{l}$ is the final load power. Since the $p_{f e}^{g}$ and $p_{e}^{g}$ in generator consist of sinusoidal fundamental component caused by the sinusoidal EMF owing to the parallel magnetization of the permanent magnet which can be calculated by analytical method precisely. The $p_{m}$ and $p_{l}$ can be read from power analyzer. Then $p_{f e}^{m}$ and $p_{e}^{m}$ can be calculated by the following method:

The stator iron loss is measured by the testing instrument of the TPS-500M which mainly measure the unit core loss coefficient of silicon lamination steel in the laboratory as the Fig.20 shows. The related correction factor is given by (60).

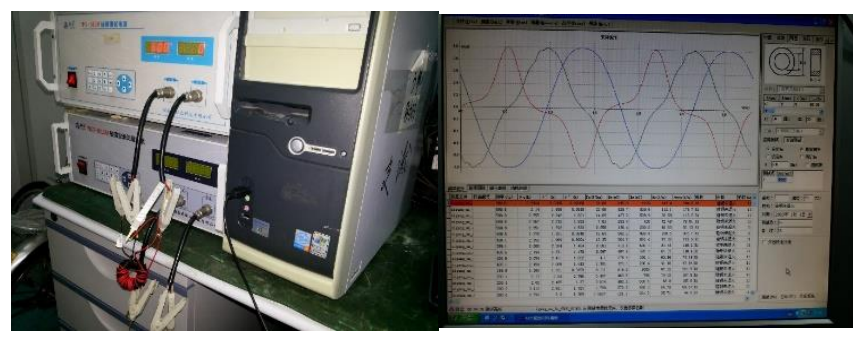

(a) the equipment

(b)the test interface

Fig.20 Test equipment iron loss and test interface of core loss per unit mass

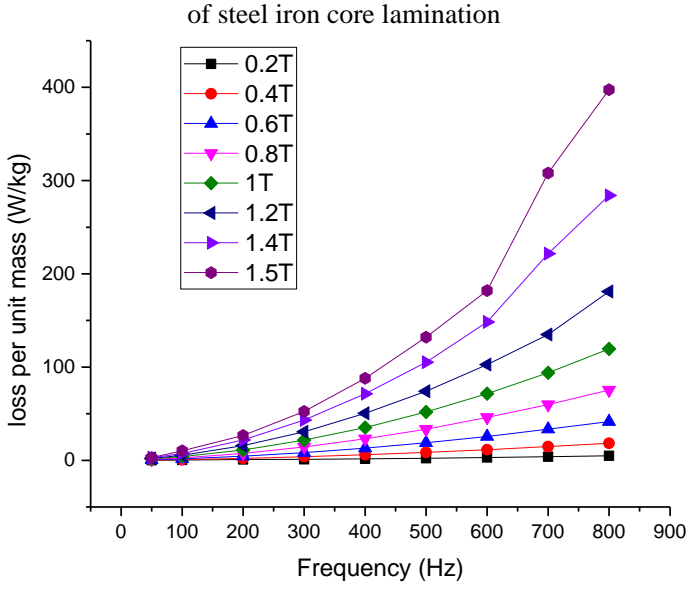

Fig. 21 test results of steel iron core lamination 
The steel iron core, made of 20WTG1500, whose testing results of core loss per unit mass of steel iron core

lamination shows in Fig.21, in which the loss per unit mass curve is fitted by BP method.

According to the characteristics of the mechanical loss of the magnetic suspension motor in the laboratory, a method to calculate the iron loss by the power coefficient method is presented, based on the phase voltage measurement. The separation results generated by the traditional method according to the test standard of the International Electrical Commission IEC60034-2: under constant speed load, the power value $\mathrm{P}$ and $U^{2}$ displaying on the power analyzer that is recorded. The method is suitable for low speed (more slowly than $10000 \mathrm{r} / \mathrm{min}$ ), which can be used for PWM control strategy of the core loss measurement.

Only when the fundamental action is considered, owing to:

$\frac{U_{d c}}{\sqrt{3}} \propto \psi_{f} \omega \propto B f=C$

Iron loss caused by Fundamental magnetic density can be expressed by the following formula:

$P=P_{h}+P_{e}=k_{h} \frac{C^{2}}{f}+k_{e} C^{2}$

So the traditional method with curve $\mathrm{P}$ and $U^{2}$ intercept approximation to calculate wind friction loss and iron loss, the traditional iron loss formula:

$P=k_{h}(1+K(\Delta B)) f B_{m}^{a}+k_{c} f^{2} B_{m}^{2}+k_{a}\left(B_{m} f\right)^{1.5}$

In above formula, $K(\Delta B)=\frac{D}{B_{p} \sum_{i=1}^{n} \Delta B_{i}}$, generally, $\mathrm{D}=0.65$;

the loss coefficients can be got by BP fitting method as

Fig.21 shows:

$K_{h}=172.716 ; K_{c}=0.271 ; K_{e}=0.698 ; \alpha=1.62$

The high frequency characteristic and the high frequency loss of high speed motor are mainly composed of 3, 5, 7 and 9 harmonic orders, which is $\mathrm{D}=0.73$

The core loss with this modification method is $295 \mathrm{~W}$ in $55000 \mathrm{r} / \mathrm{min}$, while with original method $278 \mathrm{~W}$.

The principle of measuring total $\mathrm{AC}$ resistance is:

$$
K=R_{a c} / R_{d c}=\frac{\sum_{i=1}^{n}\left|I_{i}\right|^{2}}{\left|\frac{\sum_{i=1}^{n} I_{i}}{n}\right|^{2} \times n}
$$

$$
R_{c}=R_{a} K
$$

In above formulas, $I_{i}$ is every harmonic current, $R_{a}$ is direct resistance, while $R_{c}$, is AC resistance, measured by testing method as Fig. 22 shows, of which the measurement results showing in Fig.23. AC resistance has slow growth before $1 \mathrm{kHz}$, while the $\mathrm{AC}$ inductance has smaller changes, however, which has sudden change in initial increase stage of frequency.

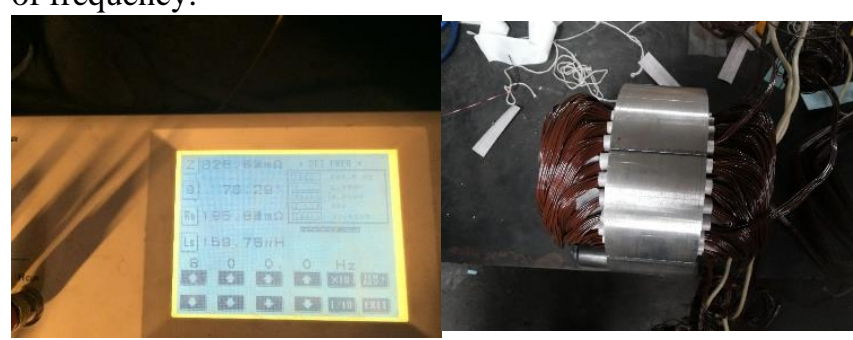

(a) the LCR instrument

(b) the coils embedded in stator Fig22. the site of measurement of AC resistence

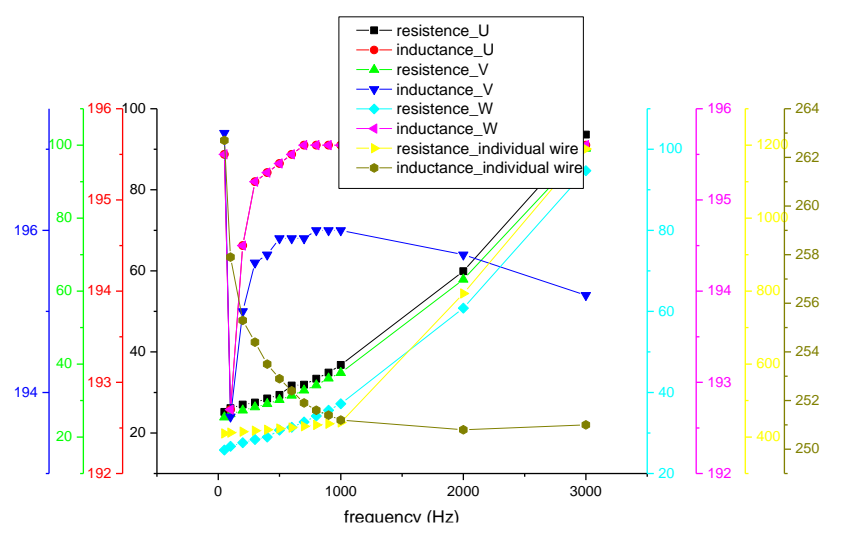

Fig.23 measurement results of AC resistance and inductance

The effective value of the phase current of the oscilloscope can be calculated, so the $\mathrm{AC}$ armature loss $p_{a}$, is $93 \mathrm{~W}$ at 55000r/min rotation speed, can be calculated as:

$p_{a}=2 I_{p}^{2} R_{c}=2 \sum_{k} I_{k}^{2} R_{c k}$

where $R_{c}$ has been illustrated and measured by (83)-(84).

Thus, the electromagnetic loss of the rotor is the total electromagnetic loss minus the total loss of the stator:

$p_{r}=p_{e}-p_{s}$

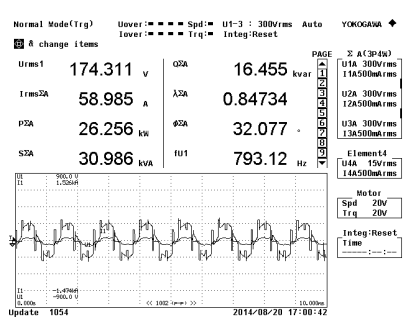

(a) full load

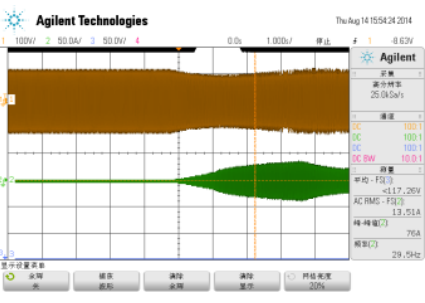

(b) whole motion course
Fig.24 display of the full load and whole motion course

During the whole load process, the display of oscilloscope shows in Fig.24(b). The data results has been recorded and 
arranged as the followings:

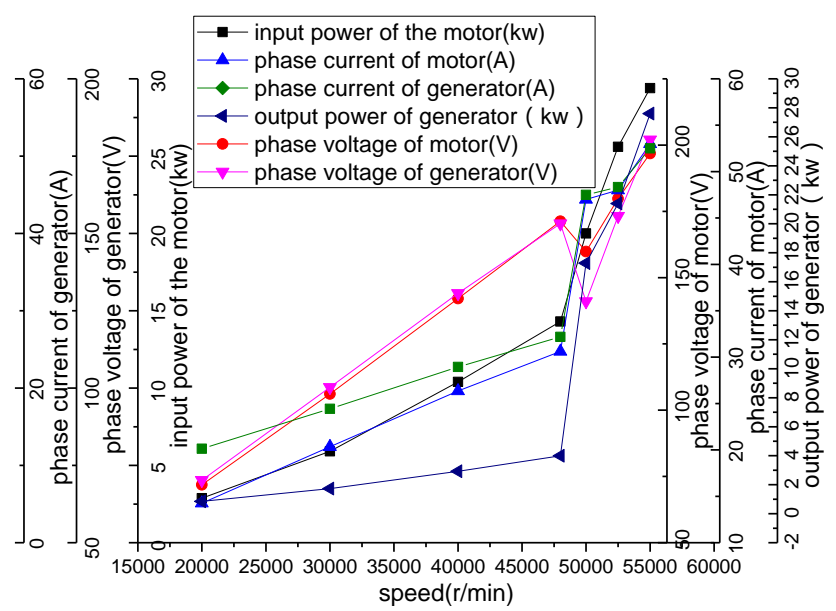

Fig.25 measurement data during whole loading process

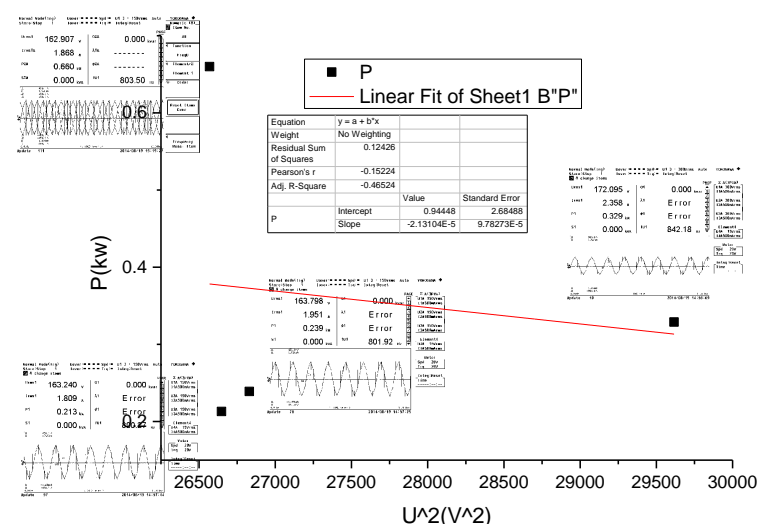

Fig.26 wind friction separation based on searching the negative slope mutation point

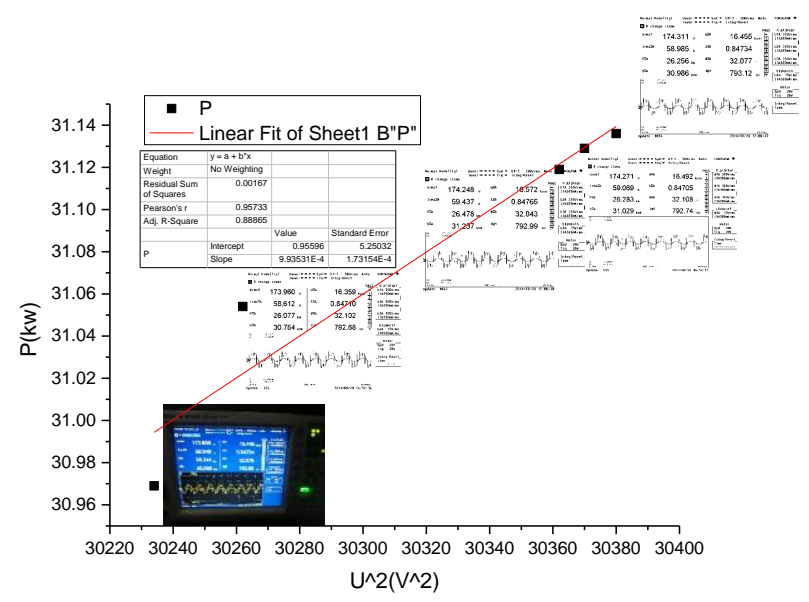

Fig.27 the fitting result of the wind friction separation

The wind friction loss should be separated by $P-U^{2}$ relation curve method to get the intercept by fitting the data point which is obtained from power analyzer(whose corresponding display interfaces located in corresponding points relatively nearby, showing in Fig.26)

The traditional method is searching the key point which leading the curve fit to the one with negative intercept, which method has weakness that the point that leading to fit the curve to the one with negative slope, which is often located in front of the former, make the curve deviation from the actual. Thus, the improved fitting method, searching the key point that lead to the curve fit to the one with negative slope, is utilized to fit the curve(Fig.27). The first point that generate the negative slope, afterwards, the points that located after that are retained, which are used for fitting the genuine curve. The wind friction loss(WFL) is 956W after improved fitting process, which corresponds to the result $865 \mathrm{~W}$, generated by traditional fitting method. The simulation result is $1161 \mathrm{~W}$ generated by CFX. The wind friction loss separation result at the speed of $55000 \mathrm{r} / \mathrm{min}$ is listed as the following diagram:

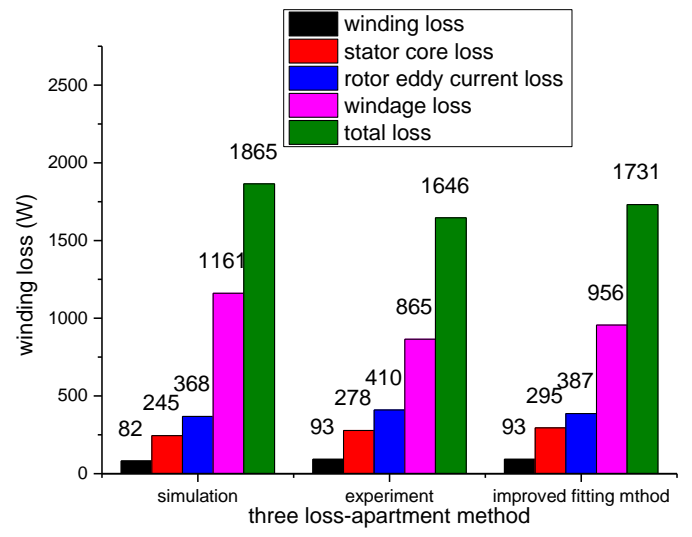

Fig.28 compare of the loss separation results

As Fig.28 shows, ECL in rotor separated by improved fitting method reaches $387 \mathrm{~W}$, which is more close to the temperature increase, when used for heat resource in CFD, of rotor surface measured in the following steps. Besides, WFL occupies the largest percentage, play the main heat source of rotor in high speed working condition, so, WFL should be considered in next optimization.

Related computation, simulation and experimental results show as the followings, which shows the ECL varieties by rotation speed:

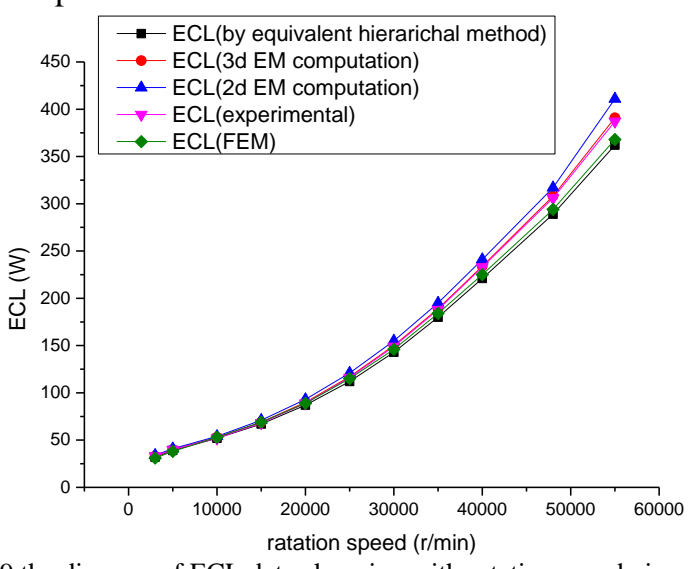

Fig.29 the diagram of ECL data changing with rotation speed via various analytical, simulation and experimental method

As the Fig.29 shows, the ECL computed by the 3-d electromagnetic method is closest to the experiment, which has more than $1.5 \%$ precise than $2-\mathrm{d}$ method and other approaches. On the other hand, the analytical model here deduced from 3-d analysis can be utilized in optimization 
and some performance prediction of HSPMSM. The equivalent hierarchical method listed in Fig.29 is dividing sleeve and permanent magnet into many thin layers to avoid curvature effect resulted from rectangular Cartesian coordinate system.

The temperature of rotor surface is measured by infrared radiation thermometer as the Fig.30(a) shows, with the upper cover left, as the Fig.30(b) shows, immediately, just right as the HSPMSM stops operating.

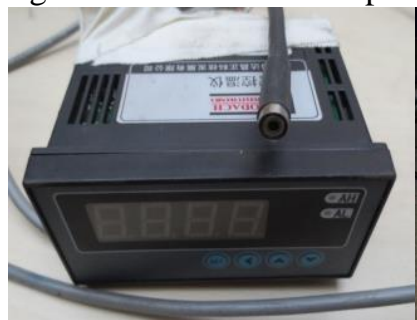

(a ) infrared radiation thermometer
Fig. 30 the site of measurement of rotor surface temperature

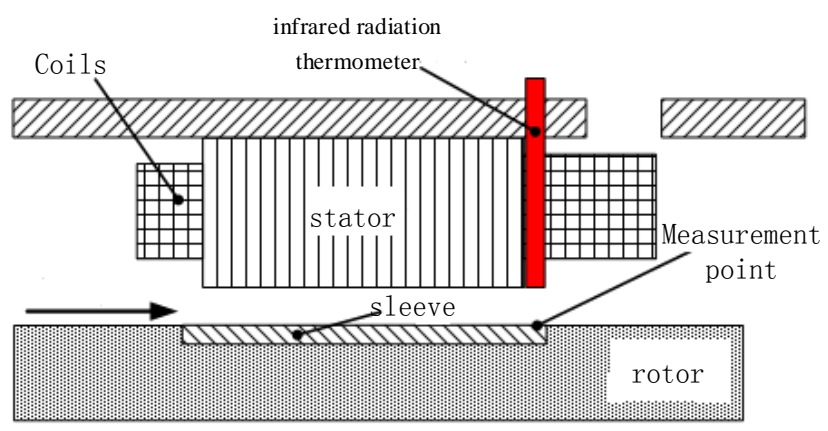

Fig.31 the sketch of measurement of rotor surface temperature

The temperature rise of rotor surface is given in Table 2

Table 2 Test measurement results of rotor surface temperature rise at stable

\begin{tabular}{|c|r|r|r|c|}
\multicolumn{5}{|c|}{ running of 48000r/min } \\
\hline speed & \multicolumn{4}{|c|}{$48000 \mathrm{r} / \mathrm{min}$} \\
\hline Axial ventilation & $\times$ & $\sqrt{ }$ & $\sqrt{ }$ & $\times$ \\
\hline Water cool & $\times$ & $\times$ & $\sqrt{ }$ & $\sqrt{ }$ \\
\hline $\begin{array}{c}\text { Rotor temperature } \\
\text { increase }\end{array}$ & $95 \mathrm{~K}$ & $9 \mathrm{~K}$ & $8 \mathrm{~K}$ & $89 \mathrm{~K}$ \\
\hline
\end{tabular}

The temperature rise of the rotor surface is measured by infrared radiation thermometer, reaching $95 \mathrm{~K}+28 \mathrm{~K}$ (ambient temperature). The temperature rise of the other part of the motor body is measured by thermistor PT100, whose

placement location is showing as:

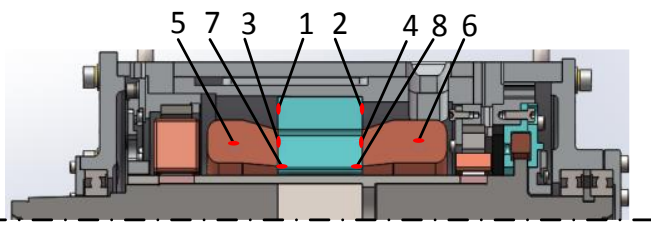

Fig. 32 Probe position of thermal resistors in high-speed machine and temperature rise curve

The maximum temperature of HSPMSM exists in coils, which has F-level insulation, and stators, reach $131{ }^{\circ} \mathrm{C}$ and $128^{\circ} \mathrm{C}$ respectively. After adding water cooling, the temperature can decrease more than $19^{\circ} \mathrm{C}$ at least. Besides, the temperature of rotor surface, with the slot surface, holds less than $125^{\circ} \mathrm{C}$, which keeps sleeve's strength and magnetic performance of permanent magnet safe.

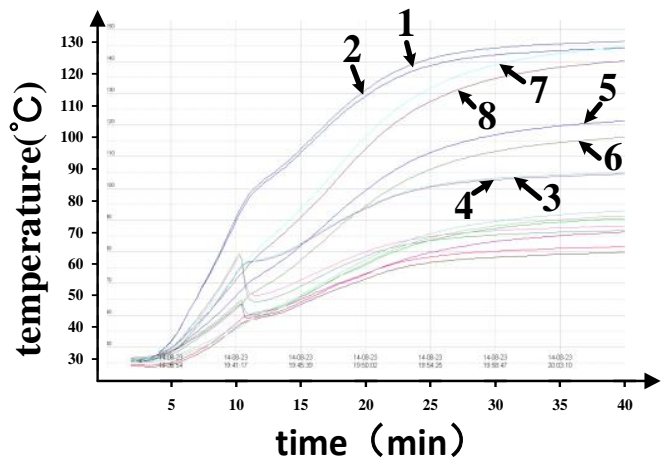

Fig.33 temperature increase vs time

The temperature measured by those PT100, embedded as Fig.32 shows, is showing in Fig.33. The highest temperature rise in motor is iron core, the next is the inner surface face to the rotor surface.

\section{THE RESULTS AND CONCLUSIONS}

The loss is less $17 \%$ than the original one after MOO process, decreasing from $356.7 \mathrm{~W}$ to $294 \mathrm{~W}$, with appropriate treatment of the conflict among the sleeve thickness, outer diameter of rotor and air-gap length. The maximum temperature in sleeve and the permanent magnet is also less $11 \%$ and $16 \%$ respectively than the original design model. Both of the above results are all configured by FEA and tests. Though, the ECL results calculated by the $3-d$ electromagnetic method is closest to the experiment, so the expression of the ECL generated from that method should be better chosen as the optimization objective model, which can be improved in follow-up improvement.

\section{ACKNOWLEDGEMENT}

SUPPORTED BY THE FUNDAMENTAL RESEARCH FUNDS FOR THE CENTRAL UNIVERSITIES. NATIONAL NATURE SCIENCE FOUNDATION OF CHINA:61573032, 61421063 AND 61403015.

References

[1] Yulong, L. Xing, L. Yi and C. Feng, "Effect of air gap eccentricity on rotor eddy current loss in high speed PMSM used in FESS," Electromagnetic Launch Technology (EML), 2014 17th International Symposium on, La Jolla, CA, pp. 1-6, 2014.

[2] A. Hemeida, P. Sergeant and H. Vansompel, "Comparison of Methods for Permanent Magnet Eddy-Current Loss Computations With and Without Reaction Field Considerations in Axial Flux PMSM," in IEEE Transactions on Magnetics, vol. 51, no. 9, pp. 1-11, 2015.

[3] F. Dubas and A. Rahideh, "Two-Dimensional Analytical PermanentMagnet Eddy-Current Loss Calculations in Slotless PMSM Equipped With Surface-Inset Magnets," in IEEE Transactions on Magnetics, vol. 50, no. 3, pp. 54-73, 2014.

[4] X. Yongxiang, Y. Qingbing, Z. Jibin and W. Hao, "Influence of periodic carrier frequency modulation on stator steel core loss and rotor eddy current loss of permanent magnet synchronous motor," Electrical Machines and Systems (ICEMS), 2014 17th International Conference on, Hangzhou, pp. 2094-2100, 2014.

[5] K. H. Kim, H. I. Park, S. M. Jang, D. J. You and J. Y. Choi, "Comparative Study of Electromagnetic Performance of High-Speed Synchronous Motors With Rare-Earth and Ferrite Permanent Magnets," in IEEE Transactions on Magnetics, vol. 52, no. 7, pp. 1-4, July 2016.

[6] A. N. Marashi, K. Abbaszadeh and F. R. Alam, "Analysis and reduction of magnet eddy current losses in surface mounted permanent magnet machines," Electrical Engineering (ICEE), 2014 22nd Iranian Conference on, pp. 782-786, Tehran, 2014.

[7] T. C. Jeong et al., "Current Harmonics Loss Analysis of 150-kW Traction Interior Permanent Magnet Synchronous Motor Through Co- 
Analysis of d-q Axis Current Control and Finite Element Method," in IEEE Transactions on Magnetics, vol. 49, no. 5, pp. 2343-2346, 2013.

[8] X. Liu and B. Han, "The Multiobjective Optimal Design of a TwoDegree-of-Freedom Hybrid Magnetic Bearing," in IEEE Transactions on Magnetics, vol. 50, no. 9, pp. 1-14, 2014

[9] E. P. Furlani, S. Reznik and W. Janson, "A three-dimensional field solution for bipolar cylinders," in IEEE Transactions on Magnetics, vol. 30, no. 5, pp. 2916-2919, Sep 1994..

[10] Yamazaki K, Watari S. Loss analysis of permanent-magnet motor considering carrier harmonics of PWM inverter using combination of 2-D and 3-D finite-element method[J]. IEEE Transactions on Magnetics, 2005, 41(5):1980-1983.

[11] Yamazaki K, Abe A. Loss Analysis of Interior Permanent Magnet Motors Considering Carrier Harmonics of PWM Inverters Using 3-D Nonlinear Time-Stepping Finite Element Method[C]// Electromagnetic Field Computation, 2006, Biennial IEEE Conference on. 2006:325-325.

[12] Chen L, Wang J, Nair S S. An Analytical Method for Predicting 3-D Eddy Current Loss in Permanent Magnet Machines Based on Generalized Image Theory[J]. IEEE Transactions on Magnetics, 2016 52(6):1-11.9.

[13] Yamazaki K, Abe A. Loss Analysis of Interior Permanent Magnet Motors Considering Carrier Harmonics and Magnet Eddy Currents Using 3-D FEM[C]// Electric Machines \& Drives Conference, 2007. IEMDC '07. IEEE International. IEEE, 2007:904-909.

[14] Kawase Y, Yamaguchi T, Ono Y, et al. Magnetic field and stress analysis of interior permanent magnet motor with off-centered rotor using 3-D finite element method[C]// Xxth International Conference on Electrical Machines. IEEE, 2012:89-93.

[15] Kouhia R, Arkkio A, Aydin U, et al. Multiaxial magneto-mechanical modelling of electrical machines with hysteresis[C]// Iet International Conference on Power Electronics, Machines and Drives. 2016.

[16] Zhang T, Zhu H Q, Sun X D, et al. Strength analysis on high-speed permanent magnet rotor using finite element method[J]. Journal of Investigative Medicine, 2014:S102-S102.

[17] J. Dong, Y. Huang, L. Jin and H. Lin, "Comparative Study of Surface-Mounted and Interior Permanent-Magnet Motors for HighSpeed Applications," in IEEE Transactions on Applied Superconductivity, vol. 26, no. 4, pp. 1-4, June 2016.

[18] A. Arkkio, T. Jokinen, E. Lantto, "Induction and permanent-magnet synchronous machines for high-speed applications", Proc. 8th Int. Conf. Electr. Mach. Syst. (ICEMS), pp. 871-876, Sep. 2005.

[19] Aimin Zhou, Yaochu Jin, Qingfu Zhang, B. Sendhoff and E. Tsang, "Combining Model-based and Genetics-based Offspring Generation for Multi-objective Optimization Using a Convergence Criterion," 2006 IEEE International Conference on Evolutionary Computation, Vancouver, BC, 2006, pp. 892-899.

[20] S. R. Cove, M. Ordonez, F. Luchino and John E. Quaicoe, “Applying Response Surface Methodology to Small Planar Transformer Winding Design", IEEE Trans. Ind. Electron., vol. 60, no.2, pp 483-493, 2013.

[21] H-R. Choi, and G-H. Choe, "A multiobjective parametric optimization for passenger-car steering actuator", IEEE Trans. on Ind.Electron.,vol.57,no. 3, pp. 900-908, 2010

[22] Zhou, Aimin, et al. "Prediction-Based Population Re-initialization for Evolutionary Dynamic Multi-objective Optimization." International Conference on Evolutionary Multi-Criterion Optimization SpringerVerlag, 2007:832-846.

[23] J. Xing, F. Wang, T. Wang, Y. Zhang, "Study on antidemagnetization of magnet for high speed permanent magnet machine",IEEE Trans. Appl. Supercond., vol. 20, no. 3, pp. 856-860, Jun. 2010.

[24] C. Zwyssig, J. W. Kolar, S. D. Round, "Megaspeed drive systems: Pushing beyond 1 million r/min",IEEE/ASME Trans. Mechatronics, vol. 14, no. 5, pp. 564-574, Oct. 2009

[25] Gao, Yuelin, and M. Qu. "Multi-objective Particle Swarm Optimization Algorithm Based on the Disturbance Operation." Artificial Intelligence and Computational Intelligence Third International Conference, Aici 2011, Taiyuan, China, September 24-25, 2011, Proceedings 2011:3421-3423.

[26] Y. J. Zheng, B. Zhang and Z. Cheng, "Hyper-heuristics with penalty parameter adaptation for constrained optimization," 2014 IEEE Congress on Evolutionary Computation (CEC), Beijing, 2014, pp. 1883-1889.

[27] B. Zhang, J. h. Duan, H. y. Sang, J. q. Li and H. Yan, "A new penalty function method for constrained optimization using harmony search algorithm," 2014 IEEE Congress on Evolutionary Computation (CEC), Beijing, 2014, pp. 853-859.

[28] C. Saha, S. Das, K. Pal and S. Mukherjee, "A Fuzzy Rule-Based Penalty Function Approach for Constrained Evolutionary
Optimization," in IEEE Transactions on Cybernetics, vol. 46, no. 12 pp. 2953-2965, Dec. 2016.

[29] M. Malek-Mohammadi, C. R. Rojas and B. Wahlberg, "A Class of Nonconvex Penalties Preserving Overall Convexity in OptimizationBased Mean Filtering," in IEEE Transactions on Signal Processing, vol. 64, no. 24, pp. 6650-6664, Dec.15, 152016.

[30] Y. Chen, W. Yuan, M. Zhang and T. A. Coombs, "The Experiment to Evaluate the AC Loss of 2G HTS Windings in the Application of Rotating Electric Machines," in IEEE Transactions on Applied Superconductivity, vol. 22, no. 3, pp. 4705204-4705204, June 2012.

[31] W. Chen, G. Deng, C. Zhou and Z. Yuan, "Numerical simulation and experiment study on the resistance loss of glue pipeline transportation," 2016 17th International Conference on Electronic Packaging Technology (ICEPT), Wuhan, 2016, pp. 138-141.

[32] P. Chrin, M. David, P. Maussion, J. Saint-Michel, E. Fournier and L. Bun, "Modeling iron, mechanical and rotor copper losses in induction machine with the design of experiments," IECON 2014 - 40th Annual Conference of the IEEE Industrial Electronics Society, Dallas, TX, 2014, pp. 729-735

[33] J. H. Lee and H. S. Song, "Loss \& efficiency evaluations of SynRM according to windings type by coupled Preisach models \& FEM and experiment," 2012 IEEE Energy Conversion Congress and Exposition (ECCE), Raleigh, NC, 2012, pp. 884-891.

[34] P. Rasilo, E. Dlala, K. Fonteyn, J. Pippuri, A. Belahcen, and A Arkkio,"Model of laminated ferromagnetic cores for loss prediction in electrical machines," IET Electr. Power Appl., vol. 5, no. 7, pp. 580588,Aug. 2011.

[35] D. Ilina, "Experimental Determination of Moment to Inertia and Mechanical Losses vs. Speed, in Electrical Machines”, Int. Symp. On Advanced Topics in Electrical Engineering, 2011

[36] D. Bauer, P. Mamuschkin, H. C. Reuss and E. Nolle, "Influence of parallel wire placement on the AC copper losses in electrical machines," 2015 IEEE International Electric Machines \& Drives Conference (IEMDC), Coeur d'Alene, ID, 2015, pp. 1247-1253.

[37] J. Bonifacio and R. Kennel, "Online copper-loss minimization of interior permanent magnet synchronous machines for automotive applications: A geometrical approach," 2015 4th International Conference on Electric Power and Energy Conversion Systems (EPECS), Sharjah, 2015, pp. 1-6.

[38] T. Shirakawa, G. Yamasaki, K. Umetani and E. Hiraki, "Copper loss analysis based on extremum co-energy principle for high frequency forward transformers with parallel-connected windings," IECON 2016 - 42nd Annual Conference of the IEEE Industrial Electronics Society, Florence, Italy, 2016, pp. 1099-1105.

[39] Y. Kim and K. Nam, "Copper-Loss-Minimizing Field Current Control Scheme for Wound Synchronous Machines," in IEEE Transactions on Power Electronics, vol. 32, no. 2, pp. 1335-1345, Feb. 2017

[40] K. Liu, X. Fu, M. Lin and L. Tai, "AC Copper Losses Analysis of the Ironless Brushless DC Motor used in a Flywheel Energy Storage System," in IEEE Transactions on Applied Superconductivity, vol. 26, no. 7, pp. 1-5, Oct. 2016.

[41] R. Wrobel, D. E. Salt, A. Griffo, N. Simpson and P. H. Mellor, "Derivation and Scaling of AC Copper Loss in Thermal Modeling of Electrical Machines," in IEEE Transactions on Industrial Electronics, vol. 61, no. 8, pp. 4412-4420, Aug. 2014.

[42] D. A. Gonzalez and D. M. Saban, "Study of the Copper Losses in a High-Speed Permanent-Magnet Machine With Form-Wound Windings," in IEEE Transactions on Industrial Electronics, vol. 61 , no. 6, pp. 3038-3045, June 2014

[43] K. Emori, T. Shimizu and Y. Bizen, "Discussion on design optimization of inductor loss focused on copper loss and iron loss," 2013 1st International Future Energy Electronics Conference (IFEEC), Tainan, 2013, pp. 241-245.

[44] Sleiman, M. ; Kedjar, B. ; Hamadi, A. ; Al-Haddad, K. ; Kanaan, H.Y.,"Modeling, Control and Simulation of DFIG for Maximum Power Point Tracking ” IEEE Control Conference (ASCC), 2013 9th Asian, pp. 1-6, June 2013

[45] N. Lahoud, J.Faucher, D. Malec, P.Maussion, , "Electrical Aging of the Insulation of Low Voltage Machines: Model definition and test with the Design of Experiments", Industrial Electronics, IEEE Transactions on, Vol.60, Issue 9, 2013, pp 4147-4155 